UNIVERSIDADE DE SÃO PAULO

FACULDADE DE MEDICINA DE RIBEIRÃO PRETO

DEPARTAMENTO DE MEDICINA SOCIAL

PÓS-GRADUAÇÃO EM SAÚDE NA COMUNIDADE

\title{
ESTUDO DO COTIDIANO E QUALIDADE DE VIDA DE PESSOAS COM INSUFICIÊNCIA RENAL CRÔNICA (IRC), EM HEMODIÁLISE.
}

Karina Viviani Bezerra

Orientador: Prof. Dr. Jair Lício Ferreira Santos

RIBEIRÃO PRETO 
UNIVERSIDADE DE SÃO PAULO

FACULDADE DE MEDICINA DE RIBEIRÃO PRETO

DEPARTAMENTO DE MEDICINA SOCIAL

PÓS-GRADUAÇÃO EM SAÚDE NA COMUNIDADE

\section{ESTUDO DO COTIDIANO E QUALIDADE DE VIDA DE PESSOAS COM INSUFICIÊNCIA RENAL CRÔNICA (IRC), EM HEMODIÁLISE.}

Dissertação apresentada ao Departamento de Medicina Social da Faculdade de Medicina de Ribeirão Preto da Universidade de São Paulo, para obtenção do título de Mestre em Saúde na Comunidade.

Orientador: Prof. Dr. Jair Lício Ferreira Santos

RIBEIRÃO PRETO 
"Tantas vezes pensamos ter chegado, tantas vezes precisamos ir mais além..."

(Fernando Pessoa) 


\section{AGRADECIMENTOS}

Agradeço a meus pais, Rosane e Edson, por sempre me incentivarem a estudar, apoiando e acompanhando mais essa etapa da minha vida! Amo vocês!

Ao professor Jair Lício Ferreira Santos, por essa grande oportunidade de desenvolver este trabalho, mostrando-se sempre disponível, aceitando minhas idéias, recebendo-me com atenção, valorizando cada etapa desse trabalho. Muito obrigada!

Ao meu irmão André, por sempre ter-me ajudado, desde o início das disciplinas, com as impressões de textos, digitações. E mesmo agora estando tão longe, sei que torce por mim! Amo você, meu irmão!

À minha irmã Juliana, que sempre me apoiou e incentivou a não desistir, auxiliando-me no que fosse preciso, com digitações e impressões. Te amo, irmãzinha!

À professora Aldaísa Cassanho Forster, por ter-me ajudado na conceituação do projeto, a fim de que eu pudesse ingressar na pós-graduação desse departamento. Sua ajuda foi fundamental, colaborando muito com a minha qualificação. Saiba que a admiro muito como pessoa e como profissional!

À professora Luzia lara Pfeifer, pelas valiosas sugestões no exame de qualificação e defesa, as quais me ajudaram muito com o desenvolvimento desse trabalho.

À professora Lícia Barcelos Souza, por ter participado da banca de qualificação e defesa, com valiosas observações e sugestões.

Ao Mario Isicawa, pela digitação dos questionários, sempre disposto a ajudar-me.

À Terapeuta Ocupacional Luciene Vaccaro de Morais, pelo incentivo em 
relação ao mestrado e pela ajuda na utilização do questionário SAOF.

À Carolina Cecília Bruno, Mônica Elisabet Knack, Solange Pedersoli e Regina Helena Greggi de Alcântara, do Departamento Medicina Social da FMRP/USP, pela disponibilidade para o que fosse preciso.

À minha querida tia Débora, à Silvia, ao meu cunhado Diego, que sempre, principalmente nos finais de semana, perguntavam e torciam para que tudo desse certo, sempre compartilhando momentos difíceis da minha vida. É nesses momentos que sabemos quem realmente se importa com a gente, Muito obrigada!

À minha querida amiga, e também Terapeuta Ocupacional, Grasielle Silveira Tavares, por ter-me recebido em sua casa a fim de que eu que eu pudesse cursar as disciplinas e colher os dados, recebendo-me sempre com muito carinho e ajudando no que fosse preciso. Muito obrigada por sua sincera amizade!

À amiga Daniela Seabra, também aluna da pós, pelos momentos de ensino compartilhados juntos às preocupações e angústias (principalmente com relação às aulas de estatística). Ainda bem que tudo deu certo!

À equipe da UTR e da hemodiálise do HCRP, principalmente ao Dr. José Abrão Cardeal da Costa, às enfermeiras Maristela do Carmo P. Candido, Heloisa Terumi Tamaributi e Ércia Missão Koto dos Reis, por ter permitido a coleta dos dados e pela colaboração no que fosse preciso.

À equipe do SENERP, principalmente ao Dr. Miguel Moises Neto e à Antonieta, pela permissão para a coleta de dados e ajuda no que fosse necessário.

A todos os pacientes que participaram desta pesquisa e mesmo aos que não conseguiram, pois sem essa ajuda o presente trabalho não teria sido realizado. Muito obrigada!

Ao Rodrigo e Cristiane Minot, pela grande colaboração na metodologia, 
tabelas e formatações desse trabalho, sempre atenciosos aos meus pedidos. Muito obrigada!

À Suely Bichuet, por ter-me ajudado a encontrar o equilíbrio necessário para viver, fazendo com que cada vez mais e mais eu acreditasse em mim.

A Deus, por não ter-me deixado desistir quando desanimei. Ele sempre esteve me protegendo em cada instante da minha vida! 
DEDICATÓRIA

Dedico este trabalho a todas as pessoas que fazem hemodiálise, pois para mim, são pessoas que expressam através de seus atos, força, persistência e determinação. 


\section{SUMÁRIO}

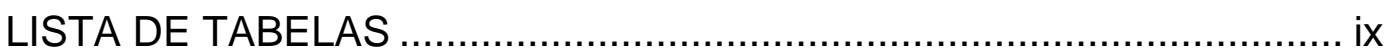

LISTA DE ABREVIATURAS .............................................................ii

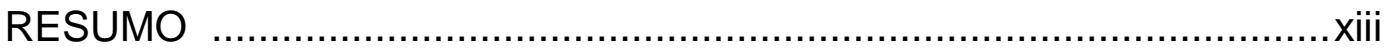

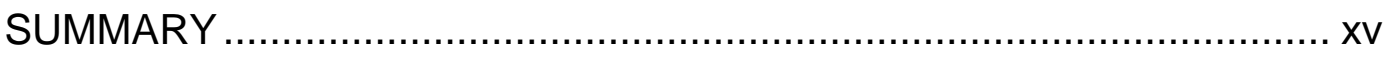

APRESENTAÇÃO ……………....................................................

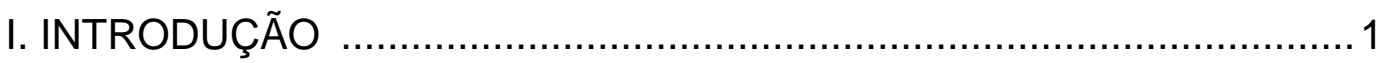

1.1 Algumas considerações acerca da IRC ....................................

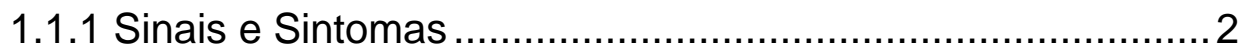

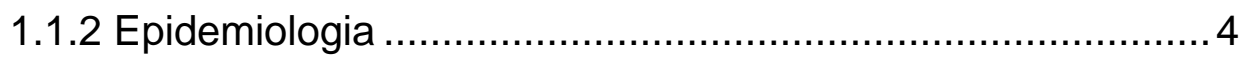

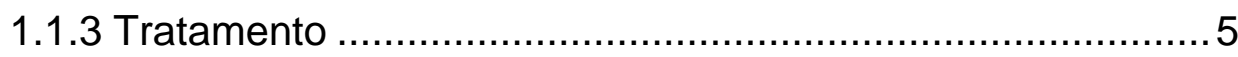

1.2 Cotidiano e adoecimento das pessoas com IRC .......................

1.3 A assistência da Terapia Ocupacional.....................................10

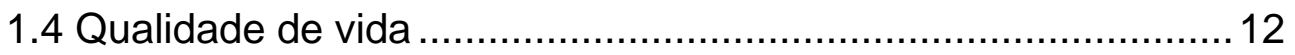

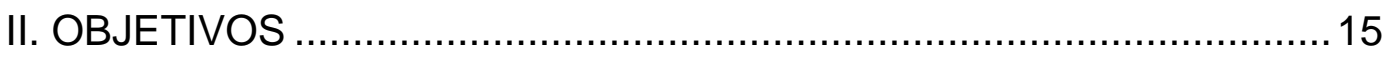

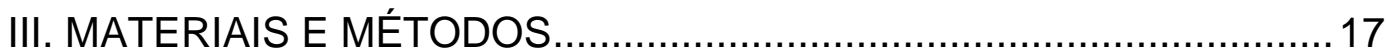

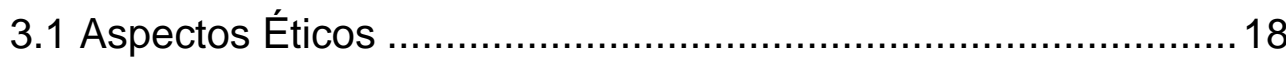

3.2 Desenho do Estudo e Período ...................................................... 18

3.3 Casuística, população e amostra.............................................18

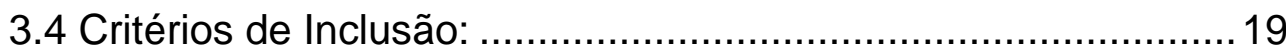

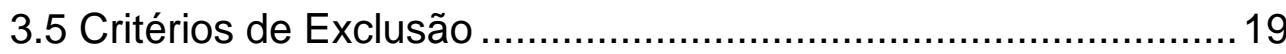




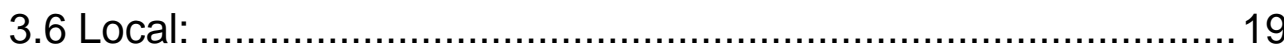

3.6.1 Caracterização da UTR ...................................................19

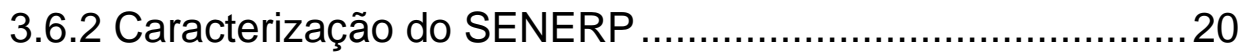

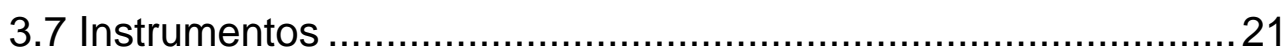

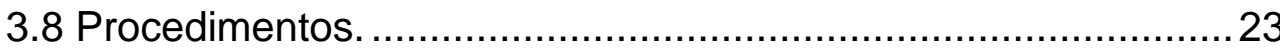

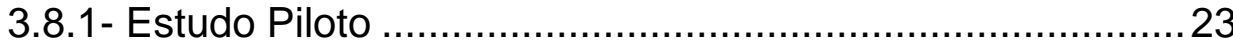

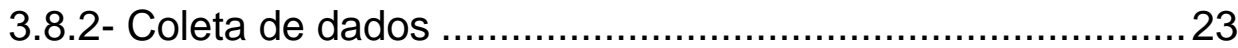

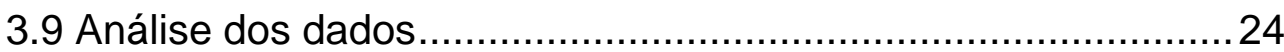

IV. RESULTADOS

4.1 Caracterização do perfil sócio-demográfico ………………......26

4.2 Avaliação do questionário SAOF .............................................31

4.3 Avaliação do questionário WHOQOL-bref .................................31

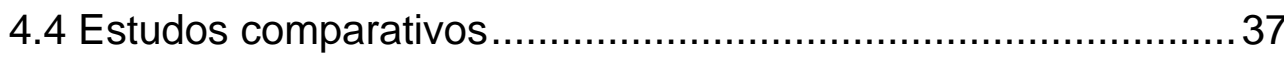

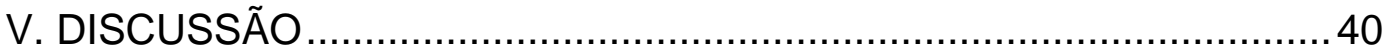

5.1 Aspectos sócio demográficos e clínicos ………...................... 41

5.2 Auto avaliação do funcionamento Ocupacional (SAOF) ............. 44

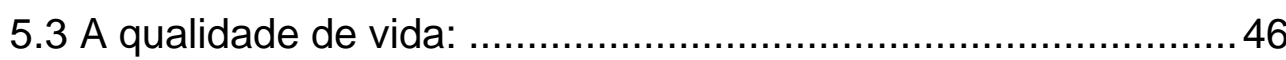

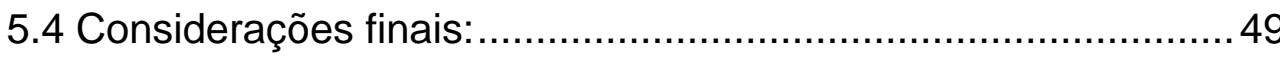

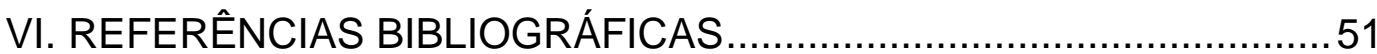

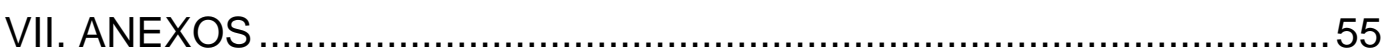




\section{LISTA DE TABELAS}

Tabela 1 - Caracterização do grupo etário em relação ao sexo

Tabela 2 - Caracterização do grupo etário em relação ao local 26

Tabela 3 - Caracterização do sexo em relação ao local

Tabela 4 - Caracterização do local de residência em relação ao meio de transporte

Tabela 5 - Caracterização do estado civil .28

Tabela 6 - Caracterização dos anos de estudo em relação ao grupo de renda ....28

Tabela 7 - Caracterização do grupo de renda em relação ao desempenho de atividade 29

Tabela 8 - Caracterização do tempo em anos de HD em relação ao local .29

Tabela 9 - Caracterização do tempo em anos em relação ao auxilio de pessoas

Tabela 10- Médias e desvios padrão das respostas individuais obtidas na aplicação do Questionário SAOF segundo cada área de referência .....31

Tabela 11 - Média dos escores da escala WHOQOL-bref - domínio Físico por idade e sexo 
Tabela 12 - Média dos escores da escala WHOQOL-bref - domínio Psicológico por idade e sexo.

Tabela 13 - Média dos escores da escala WHOQOL-bref - domínio Relações Sociais por idade e sexo 32

Tabela 14 - Média dos escores da escala WHOQOL-bref - domínio Meio Ambiente por idade e sexo. 33

Tabela 15 - Média dos escores da escala WHOQOL-bref domínio Saúde em Geral, por idade e sexo. 33

Tabela 16 - Média dos escores da escala WHOQOL-bref em cada domínio segundo condição marital.

Tabela 17 - Média dos escores da escala WHOQOL-bref segundo quantidade de pessoas na residência:

Tabela 18 - Média dos escores da escala WHOQOL-bref segundo os anos de estudo:

Tabela 19 - Média dos escores da escala WHOQOL-bref, em cada dominio segundo o tempo em anos de hemodiálise

Tabela 20 - Média dos escores da escala WHOQOL-bref, em cada domínio segundo o tempo de hemodiálise (1 ano ou mais)

Tabela 21 - Média dos escores da escala WHOQOL-bref em cada dominio segundo o meio de transporte.

Tabela 22 - Resultados dos testes de comparação dos escores de qualidade de vida (WHOQOL-bref) - Domínio Físico 
Tabela 23 - Resultados dos testes de comparação dos escores de qualidade de vida (WHOQOL-bref) - Domínio Psicológico........................................38

Tabela 24 - Resultados dos testes de comparação dos escores de qualidade de vida (WHOQOL-bref) - Domínio Social ..............................................38

Tabela 25 - Resultados dos testes de comparação dos escores de qualidade de vida (WHOQOL-bref) - Domínio Meio Ambiente .39

Tabela 26 - Resultados dos testes de comparação dos escores de qualidade de vida (WHOQOL-bref) Geral 39 


\section{LISTA DE ABREVIATURAS}

HC: Hospital das Clínicas.

IRC: Insuficiência Renal Crônica.

IRCs: Insuficientes Renais Crônicos.

SENERP: Serviço de Nefrologia de Ribeirão Preto.

UTR: Unidade de Hemodiálise e Transplante Renal.

T.O: Terapia Ocupacional.

SBN: Sociedade Brasileira de Nefrologia.

SUS: Serviço Único de Saúde.

SAOF: Self Assessment of Occupational Functioning.

WHOQOL-bref: World Health Organization Quality of Life Group.

DPAC: Diálise Peritoneal Ambulatorial Contínua.

DPA: Diálise Peritoneal Automatizada.

DPI: Diálise Peritoneal Intermitente.

HD: Hemodiálise.

AVD: Atividades da Vida Diária 


\section{RESUMO}

A insuficiência renal crônica (IRC) é considerada um grande problema de saúde pública, devido às altas taxas de morbidade e mortalidade. Os insuficientes renais crônicos (IRCs) apresentam várias dificuldades em seu cotidiano, como: constantes visitas ao médico, sessões de hemodiálise e restrições alimentares; fatores que desestruturam seu cotidiano e comprometem sua qualidade de vida. Essa pesquisa tem como objetivo avaliar a percepção das pessoas com IRC com relação a atividades cotidianas e ocupacionais, junto a dois serviços públicos de saúde em Ribeirão Preto; assim como avaliar a percepção da qualidade de vida dentro dos seguintes domínios: Físico, Psicológico, Social e Meio Ambiente. A amostragem analisada foi composta por 70 indivíduos adultos que recebiam hemodiálise, de ambos os sexos (35 homens e 35 mulheres), com idades variando entre 17 e 60 anos. Os dados foram coletados através da aplicação de três questionários: o primeiro estruturado para a caracterização de dados sóciodemográficos, o segundo para a auto-avaliação do Funcionamento Ocupacional (SAOF) e o terceiro para a Avaliação de Qualidade de Vida da Organização Mundial da Saúde (WHOQOL-bref). Os instrumentos foram úteis e de importância para avaliar a qualidade de vida e o desempenho ocupacional dessas pessoas: observouse na aplicação do SAOF que, embora a predominância dos resultados possa ser considerada satisfatória, a área com maior escolha da alternativa "necessidade de melhora" foi a de hábitos e valores (20\% e 20,5\%, respectivamente). Apesar da porcentagem não ser muito alta, é aqui que as dificuldades com relação à organização do cotidiano são mais evidentes, principalmente frente às mudanças de rotinas e expectativas quanto ao futuro. Na aplicação do WHOQOL-bref, constatou- 
se que os pacientes que se auto-avaliaram com menor média de qualidade de vida são os que têm cônjuge (54.6\%), os que estão há mais de um ano em hemodiálise (52.6\%), e os pacientes do sexo masculino (58.6\%). A variável "anos de escolaridade" mostrou que as pessoas com menos instrução apresentam menor avaliação de sua qualidade de vida nos domínios Físicos (51.1\%), Social (61.0\%) e Meio Ambiente (61.1\%). Entende-se, portanto, que a Terapia Ocupacional apresenta recursos instrumentais para a reestruturação do cotidiano desses pacientes, podendo constituir-se em valiosa contribuição para a assistência.

Palavras- chave: insuficiência renal crônica, hemodiálise, cotidiano e qualidade de vida. 


\section{SUMMARY}

The chronic renal failure (CRF) is considered a great problem of public health due to the high rates of morbidity and mortality. Persons with chronic renal insufficients (CRIs) present various difficulties in their daily life such as constant visits to the doctor, hemodialysis sessions and food restrictions disorganizing therefore their daily life and quality of life. This research has the aim to evaluate the perception of persons with CRF about the daily life in relation to their occupational functioning in two public health services in Ribeirão Preto and evaluate the perception of quality of life within the following domains: Physical, Psychological, Social and Environmental. The sample studied was composed of 70 adult individuals undergoing hemodialysis, of both genders ( 35 men and 35 women) in ages varying between 17 and 60 . The data was gathered through the application of three questionnaires: one was structured for the characterization of social-demographic data, the second for Self Assessment of Occupational Functioning (SAOF) and the third for evaluation of the Quality of Life according to the World Health Organization's Quality of Life Evaluation Instrument (WHOQOL-bref). The instruments were useful and of importance to evaluate the quality of life and the occupational performance of those persons. It was noticed from the SAOF that although the most of the results might be considered satisfactory, the area with the greatest choice of the alternative "necessity of improvement" was the one of habits and values (20\% and $20.5 \%$ respectively). Despite the percentage not being high, there were the difficulties regarding the daily life mainly in face of changes in routine as well as expectations regarding the future. From the application of the WHOQOL-bref, it could be noticed that the patients who self-evaluated themselves with the lowest average of quality of life are the ones who 
have spouses (54.6\%), the ones who have been undergoing hemodialysis for over a year $(52.6 \%)$ and the male patients $(58.6 \%)$. The variable years of schooling demonstrated that the persons with less education present lower evaluation of their quality of life in following domains: Physical $(51,1 \%)$, Social $(61,0 \%)$ and Environment $(61.1 \%)$. It is understood, therefore, that the Occupational Therapy presents instrumental resources for the reorganization of those patients' daily life, constituting a valuable contribution for assistance.

Key-worlds: chronic renal failure, hemodialysis, daily life and quality of life 


\section{APRESENTAÇÃO}

Iniciei em Janeiro de 2.001 o aprimoramento de Terapia Ocupacional em psquiatria no HCRP. A minha última passagem foi no Serviço de Interconsulta em Saúde Mental (SISMen) em julho de 2.002, quando dei continuidade a um grupo de Terapia Ocupacional durante a HD na UTR - setor HD do HCRP, que havia sido iniciado em fevereiro daquele mesmo ano pela aprimoranda que me antecedeu. Esse grupo teve inicio após as avaliações observadas pela Terapia Ocupacional, pois a equipe do serviço de HD solicitou o SISMen, por constatar que alguns pacientes de um determinado grupo precisavam da assistência da saúde mental. Ao término do aprimoramento em janeiro de 2.003, quando também encerrei meu trabalho junto a esse grupo, percebi o quanto havia me envolvido com esse trabalho e com as dificuldades das pessoas com IRC. Em conversa com a supervisora de Terapia Ocupacional responsável pelo serviço de interconsulta, decidimos escrever um artigo sobre essa experiência (também utilizado para essa pesquisa) juntamente com a outra Terapeuta Ocupacional que iniciou o grupo. Tal artigo instigou-me a um aprofundamento em meus estudos e ao desenvolvendo da pesquisa que gerou a presente dissertação. Embora não mais trabalhando com as pessoas envolvidas na pesquisa, tenho enorme satisfação em relatar tal experiência, pois todo o processo de realizar o grupo, escrever o artigo, fazer a dissertação e, enfim, tratar do presente assunto foi e sempre será muito gratificante. 
I. INTRODUÇÃO 


\subsection{Algumas considerações acerca da IRC}

Draibe (2002, p.179) conceitua a IRC como uma:

"... síndrome complexa conseqüente à perda, geralmente lenta e progressiva, da capacidade excretória renal. Esse conceito pode ser traduzido pela redução progressiva da filtração glomerular, principal mecanismo de excreção de solutos tóxicos gerados pelo organismo."

As principais funções dos rins são:

- Excreção de produtos finais do metabolismo (Filtração glomerular tubular);

- Manutenção do volume extracelular (Balanço $\mathrm{Na}$ e $\mathrm{H}_{2} \mathrm{O}$ );

- Manutenção da composição iônica do volume extracelular;

- Manutenção do equilíbrio ácido-base;

- Produção e excreção de hormônios e enzimas;

- Metabolismo de hormônios (insulinas).

Segundo a Sociedade Brasileira de Nefrologia (2001) devido à perda lenta e progressiva, a pessoa passa por processos adaptativos, e o paciente não apresenta os sintomas da doença, logo no início.

As doenças mais comuns que levam à IRC são: diabetes, hipertensão arterial e glomerulonefrite. $\mathrm{O}$ controle da pressão é o principal ponto de prevenção da hipertensão arterial e o diabetes uma das mais importantes causas de falência dos rins (SOCIEDADE BRASILEIRA DE NEFROLOGIA, 2001).

\subsubsection{Sinais e Sintomas}


Draibe (2002) cita a hipertensão arterial e a anemia (redução da produção de eritropoetina) como os principais sintomas decorrentes da perda da função renal. Caso a dieta hipoprotéica não seja realizada, começa a fase de descompensação, desenvolvendo-se a síndrome urêmica.

Nesses casos, a urina apresenta alteração na cor (fica parecida com coca cola), a pessoa sente dor ao urinar, dor lombar, anemia, fraqueza e náuseas (SOCIEDADE BRASILEIRA DE NEFROLOGIA, 2001).

Alguns sinais e sintomas neurológicos são: irritabilidade, tremores, dificuldade de concentração, sonolência e coma. Hálito urêmico, estomatite e anorexia são alguns sinais e sintomas gastrointestinais (DRAIBE, 2002)

As pessoas com IRC, podem também apresentar sintomas cardiovasculares (derrame pleural), hematológicos (sangramento), endocrinológicos e metabólicos, como hiperglicemia, perda de peso e fraqueza respectivamente (DRAIBE, 2002).

É importante lembrar que o doente renal crônico apresenta-se mais suscetível a infecções por transfusões sangüíneas, exemplificando-se a Hepatite B, C e AIDS (DRAIBE, 2002).

Em relação ao sistema respiratório, conforme relata Weiner et al. (1997) os pacientes com IRC, em tratamento dialítico, passam por alterações rápidas no volume e componentes bioquímicos do fluido dos seus corpos, afetando dessa forma as funções dos músculos respiratórios. 


\subsubsection{Epidemiologia}

Conforme o Censo 2005 da SBN, existem 54.311 pacientes em tratamento de diálise, sendo 48.362 pacientes em HD, 3.638 em DPAC, 2073 em DPA e 238 em DPI. É necessário ressaltar que $83 \%$ das unidades de diálise colaboraram para a realização desse Censo.

Nos estudos de Carreira e Marcon (2003), os dados estatísticos mostram que a incidência anual em pacientes em HD é em torno de 100 casos por milhão de habitantes, mas, em se tratando de custo anual, o transplante tem menor custo comparado com a diálise e HD. A maior expectativa para essas pessoas é o transplante renal, cuja busca ocorre em longas filas de espera. No entanto, o sacrifício é aliviado por uma melhor qualidade de vida nesse período.

Em termos de custos e gastos com pacientes com IRC, conforme relatos do estudo de Arredondo et al. (1998), a diálise e HD, por evento, têm um custo insignificante em relação ao transplante. Todavia, em se tratando de custo anual, o custo do transplante tem menor custo comparado à diálise e HD.

Conforme relata Sesso (2002), a IRC é uma doença com alta morbidade e mortalidade. Há aumento progressivo de incidência e prevalência de pacientes com IRC terminal no Brasil, sendo, portanto, a doença renal considerada um grande problema de saúde pública. As taxas de prevalência de IRC terminal tratadas no Brasil são cerca de quatro vezes menores que nos EUA e Japão e metade das taxas da Itália, França e Alemanha.

Em relação aos fatores de risco, os mais importantes a considerar são diabetes e idade avançada. Quanto à faixa etária, segundo dados estatísticos de 1999, cinqüenta e dois por cento dos pacientes eram do sexo masculino, vinte e seis 
por cento tinham mais de 60 anos de idade, com estimativa de aumentar essa idade nos últimos anos. Havia 2,2\% de pacientes de diálise com menos de 18 anos no Brasil e somente 297 desses com idade igual ou menor que 10 anos (SESSO, 2002).

No Brasil, nos últimos anos, o Ministério da Saúde tem investido em máquinas de HD, no fornecimento de medicamentos e na realização de transplantes (MINISTÉRIO DA SAÚDE, 2.002).

Estima-se que $95 \%$ dos tratamentos dialíticos são custeados pelo SUS. É importante ressaltar também que, segundo os dados do Ministério da Saúde (2.002), o número de transplantes no Brasil teve um aumento significativo, colocando o Brasil em segundo lugar em transplante de rim do mundo. Acredita-se, porém, que esse número ainda não seja suficiente.

\subsubsection{Tratamento}

O tratamento ocorre através da dieta hipoprotêica e uso de antihipertensivos. Em fases mais avançadas, onde ocorre a perda quase total da função renal, há a necessidade do tratamento dialítico e de transplante renal (DRAIBE, 2002).

Martins e Cesarino (2005) citam em seus estudos que os tratamentos disponíveis para as doenças renais terminais são: a Diálise Peritoneal Ambulatorial Contínua (DPAC), Diálise Peritoneal Automatizada (DPA), Diálise Peritoneal Intermitente (DPI), Hemodiálise (HD) e o transplante renal. É importante ressaltar que todos são tratamentos para aliviar os sintomas do paciente e preservar sua vida, porém nenhum deles é de caráter curativo.

Para entender cada modalidade, é necessário primeiro conceituar a diálise 
peritoneal, segundo a enciclopédia Wikipédia (2006):

"é o processo de depuração do sangue no qual a transferência de solutos e líquidos ocorre através de uma membrana semipermeável (o peritôneo) que separa dois compartimentos. Um deles é a cavidade abdominal,onde está contida a solução de diálise; o outro é o capilar abdominal, onde está contida a solução de diálise; o outro é o capilar peritoneal, onde se encontra o sangue com excesso de escórias nitrogenadas,potássio e outras substâncias. $O$ peritôneo age como um filtro, permitindo a transferência de massa entre os dois compartimentos. Consiste em um membrana semipermeável, heterogênea e com múltiplos poros de diferentes tamanhos."

Dessa forma, descreve-se agora cada modalidade, segundo a Wikipédia (2006):

DPAC: Nessa modalidade o abdómen fica sempre preenchido com líquido, sendo normalmente feitas 4 trocas por dia, o quê é o mais adequado para a maioria dos pacientes.

DPA: As trocas são feitas por um dispositivo mecânico chamado cicladora, o qual é previamente programado para realizar as trocas de acordo com as necessidades de cada paciente.

DPI: É quando ocorre intervalos entre as diálises, ou seja, durante determinado período a cavidade abdominal fica vazia, não ocorrendo o processo diálitico.

Quanto a HD entende-se, como um procedimento que depende de um dialisador (máquina) para filtrar o sangue. Trata-se de um procedimento onde 0 
sangue do paciente é retirado de uma veia por meio de uma fístula artério-venosa e levado lentamente por tubos até um filtro ligado a uma máquina. Este filtro é capaz de extrair do sangue impurezas, excesso de água e sais. Após a filtragem, o sangue limpo retorna ao paciente (BORGES, 2003).

Pode-se, portanto, constatar que o tempo gasto nesse processo acarreta a ruptura do cotidiano do indivíduo com IRC, visto que a permanência de aproximadamente 4 horas para a execução do HD gera todo um desgaste físico e emocional ao paciente.

Conforme cita Pierratos (1999), há estudos feitos no Canadá com o intuito de promover uma melhor qualidade de vida, como a HD noturna realizada em casa, numa tentativa de oferecer um tratamento de alta qualidade e baixo custo. Essa informação é extremamente relevante tendo em vista as dificuldades das pessoas que fazem HD geralmente três vezes por semana, com duração de quatro horas diárias.

Draibe (2002) relata que os programas dialíticos crônicos, HD e Diálise Peritonial Ambulatorial Contínua (DPAC) estão disponíveis no SUS (Sistema Único da Saúde) para todos os brasileiros e que esses programas proporcionam elevada sobrevida ao paciente.

Diante dos relatos dos portadores de IRC sobre suas conseqüências e formas de tratamento, observa-se uma grande desestruturação e modificação em seus cotidianos. Para uma melhor compreensão da conotação da palavra “cotidiano”, será feito um breve comentário no próximo tópico.

\subsection{Cotidiano e adoecimento das pessoas com IRC}


A palavra "cotidiano" tem origem no latim, proveniente de quotidianus, segundo Cunha (1982, p.223): “Diz-se de, ou aquilo que é diário, que sucede ou se pratica habitualmente“.

Conforme relata Benetton et al. (2003), o conceito de cotidiano começou a ser estudado pelas Ciências Sociais no século XIX, sendo entendido a partir daí como elemento constituído da trama social.

Numa linguagem mais simples, entende-se que a vida cotidiana é o dia-adia, a vida dos mesmos gestos, dos ritmos de todos os dias como: levantar nos horários certos, ir ao trabalho, à escola, preparar o café da manhã, o almoço, praticar um esporte, enfim, atividades que se fazem de uma maneira mais mecânica e automatizada (NETTO \& CARVALHO, 1996).

Entre várias discussões e críticas sobre o cotidiano, Luckacs ${ }^{1}$ (1979 apud BENETTON et al., 2003) coloca a vida cotidiana como o local de desenvolvimento humano, exemplificando através de aspectos como trabalho, linguagem, pensamento, sentimento, ações e reflexões do homem.

"O homem nasce já inserido em sua cotidianidade. 0 amadurecimento do homem significa, em qualquer sociedade, que o indivíduo adquire todas as habilidades imprescindíveis para a vida cotidiana da sociedade (camada social) em questão. É adulto quem é capaz de viver por si mesmo a sua cotidianidade." (HELLER, 2000, p.18)

O indivíduo com IRC sofre uma série de limitações, físicas, sociais e emocionais, incluindo as dificuldades no desempenho ocupacional, as restrições 
hídricas, as dietas especiais, as consultas médicas e as sessões de HD, o quê tornando a pessoa frágil e desestrutura o seu cotidiano. É extremamente importante considerar essas limitações. Em relação a isto, Lima et al. ${ }^{2}$ (1994 apud OLIVEIRA, 2000, p.16) relatam:

"Discorrer sobre o emocional do paciente renal é, antes de tudo, uma trajetória de perdas que vai além da perda da função renal. Desde o momento do diagnóstico até possível realização do transplante (única expectativa real de "cura"), o caminho do insuficiente renal crônico é atravessado por uma série de outras questões que colocam em evidência sua problemática pessoal, bem como a dinâmica familiar. “

$\mathrm{Na}$ maioria das vezes, a rotina do portador de IRC se restringe a consultas médicas, a sessões de HD três vezes por semana, geralmente, a dietas e à não execução de atividades que requeiram muito esforço, pois a maioria sente-se fraca e cansada. Muitos que são chefes da família e donas de casa, às vezes ajudam em casa mas não trabalham e fazem também algumas atividades manuais e artesanais (CARREIRA \& MARCON, 2003)

Conforme cita Bezerra et al. (2005), são inúmeras as dificuldades enfrentadas por essas pessoas, influenciando o seu dia-a-dia, o seu modo de se relacionar, seja pela dependência da máquina ou pelas idas ao médico, dificultando dessa forma o desempenho nas suas atividades ocupacionais, o quê, por conseqüência, desestrutura sua vida cotidiana.

${ }^{1}$ LUCKÁCS. Ontologia do ser social I e II. Ciências humanas, 1979.

${ }^{2}$ LIMA, A.M.C. et al. Insuficiência Renal Crônica - A Trajetória de uma Prática. In: BELLKISS. W.R. (Org.). “A Prática da Psicologia nos Hospitais”. Cap.05, p.7792. São Paulo: Pioneira. 1994. 


\subsection{A assistência da Terapia Ocupacional}

Partindo do que foi relatado sobre cotidiano, entende-se que a pessoa com IRC apresenta uma série de dificuldade na sua rotina de afazeres e a Terapia Ocupacional tem como um de seus principais objetivos reestruturar o cotidiano dessas pessoas e promover estratégias que favoreçam sua vinculação com o meio social que até então se torna desestruturada.

Medeiros (2003, p.27) relata que:

"A Terapia Ocupacional, como área de conhecimento e prática de saúde, se interessa pelos problemas do homem em sua vida de atividades. Em outras palavras, considera as atividades humanas como o produto e o meio de construção do próprio homem e busca entender as relações que este homem em atividade estabelece em sua condição de vida e saúde"

Entende-se que a atividade é de extrema importância para entender o homem na sua relação social, na sua forma de se construir.

Para o desenvolvimento desse trabalho, é importante relatar sobre as áreas de desempenho ocupacional, pois conforme cita Neistadt e Crepeau (2002):

"A Terapia Ocupacional é a arte e ciência de ajudar pessoas a realizarem atividades diárias, que são importantes para elas, apesar das incapacidades, ou deficiências, "Ocupação" em terapia ocupacional não se refere simplesmente a profissões ou a treinamentos profissionais; ocupação em terapia ocupacional 
refere-se a todas atividades que ocupam o tempo das pessoas e dão sentido as suas vidas".

$\mathrm{Na}$ Terapia Ocupacional essas áreas são denominadas de desempenho ocupacional, podendo ser divididas em atividades diárias, atividades laborativas e produtivas e atividades de lazer e diversão (AOTA ${ }^{3}, 1994$ apud NEISTADT \& CREPEAU, 2002).

Para um melhor entendimento, descreve-se abaixo as áreas de Desempenho Ocupacional definidas na terminologia Uniforme da AOTA ${ }^{4}$ (1994 apud NEISTADT \& CREPEAU, 2002):

Atividades da Vida Diária (AVD): Refere-se a arrumar-se, higiene oral, tomar banho, higiene sanitária, cuidado próprio, vestir-se, alimentar-se, rotina médica, manutenção da saúde, socialização, mobilidade funcional e mobilidade comunitária.

Atividades Profissionais e Produtivas: Administração da casa, (cuidado com a roupa, limpeza, preparação da comida, fazer compras, administração do dinheiro, manutenção do domicílio, procedimentos de segurança), cuidar dos outros, atividades educativas e atividades vocacionais (exploração vocacional, aquisição de um trabalho, planejamento da aposentadoria, participação voluntária).

Atividades de Diversão e Lazer: Exploração do Lazer e diversão e execução de jogos, lazer e diversão.

3 AOTA - AMERICAN OCUPATIONAL THERAPY ASSOCIATION. Uniform terminology for occupational therapy. American Journal of Occupational Therapy, v.48, p.1047-1054, 1994.

4 AOTA - AMERICAN OCUPATIONAL THERAPY ASSOCIATION. Uniform terminology for occupational therapy. American Journal of Occupational Therapy, v.48, p.1047-1054, 1994. 
Dessa forma, percebe-se o quanto a Terapia Ocupacional pode contribuir para o resgate de motivação para os IRCs, organizando seu cotidiano considerando que, como foi relatado, há uma série de dificuldades que fazem com que essas pessoas possam vivenciar um forte desgaste emocional, desestruturando seu desempenho ocupacional, afastando-as de seu meio social .

A Terapia Ocupacional favorece a melhoria nas áreas de desempenho ocupacional, na participação social, contribuindo para uma melhor qualidade de vida, a qual será melhor descrita no próximo tópico.

\subsection{Qualidade de vida}

Conforme coloca Ferraz (1998), o termo e conceito "qualidade de vida" surgiu nos E.U.A. após a $2^{a}$ guerra mundial, descrevendo o efeito gerado pela aquisição de bens materiais (tecnologia) na vida das pessoas, sendo posteriormente utilizado como parâmetro a ser valorizado com o intuito de resgatar avanços nas áreas da saúde e da educação.

A partir daí, forma-se um conceito elaborado pela Organização Mundial da Saúde ${ }^{5}$ (1994 apud FERRAZ, 1998, p.219), onde "Qualidade de vida" é "a percepção individual de um completo bem estar, mental e social".

Para Mastropietro (2003), a noção de qualidade de vida de uma pessoa tem recebido diferentes definições e mudanças em suas conceituações. Porém, entendese que sempre faz referência ao nível de satisfação que o sujeito elabora da vida

${ }^{5}$ ORGANIZAÇÃO MUNDIAL DA SAÚDE. Qualilty of life assesment. An annotade Blbliogrpy. Geneva: WHO (MNH/PSF/94.1), 1994. 
cotidiana. Segundo Minayo (2000, p.8):

"Qualidade de vida é uma noção eminentemente humana, que tem sido aproximada ao grau de satisfação encontrado na vida familiar, amorosa, social e ambiental e a própria estética existencial de todos os elementos que determinada sociedade considera seu padrão de conforto e bem estar.“

Ou seja, refere-se a vários aspectos da vida como o físico, o psicológico e o social, considerando o nível de satisfação do indivíduo, em cada um desses aspectos, avaliando o valor que a pessoa atribui à sua forma de viver e à importância que a vida tem para si próprio.

Ruffino (1994) considera como qualidade de vida boa ou excelente aquela em que haja um mínimo de condições para que os indivíduos desenvolvam o máximo de suas potencialidades como viver, sentir ou amar, trabalhar, produzindo bens ou serviços, ciências ou artes. Enfim, todos são seres vivos que procuram se realizar.

Do ponto de vista epidemiológico, a qualidade de vida pode ser entendida como um conceito que abrange fundamentalmente cada indivíduo, família, comunidade ou grupo populacional, em cada momento de sua existência, considerando suas necessidades e aspectos físicos que são suas características incluindo a idade, sexo e outros atributos individuais,

No aspecto da qualidade de vida, há três elementos básicos: o direito à qualidade de vida, o acesso aos bens e serviços coletivos e o espaço social enquanto espaço histórico cultural (MEDRONHO et al., 2002). 
Em pesquisas, a qualidade de vida pode ser avaliada por vários tipos de instrumentos, pois conforme relata Ferraz (1998) há vários instrumentos, métodos e técnicas para avaliar a qualidade de vida ou a capacidade funcional de pacientes com as mais diversas doenças, podendo ser divididos em instrumentos genéricos e específicos.

\section{Instrumentos Genéricos:}

São aplicáveis a uma grande variedade de populações incluindo aspectos relativos à função, disfunção e desconforto emocional e físico sendo de extrema importância para a qualidade de vida da população.

\section{Instrumentos Específicos:}

São instrumentos capazes de avaliar a qualidade de vida dos pacientes, apresentando uma maior capacidade de detecção com maior suscetibilidade à alteração, propriedade esta muito importante quanto à avaliação das modalidades terapêuticas, como por exemplo coronariopatia, diabetes mellitus. Sendo ainda aplicáveis a uma determinada população de pacientes, como, por exemplo, idosos.

Conforme todos os aspectos citados e explicados, observa-se o quanto o cotidiano das pessoas com IRC tem sido desestruturado e interrompido, devido às condições físicas e emocionais que influenciam em sua qualidade de vida. Portanto, é necessário reorganizá-lo e reestruturá-lo, a fim de que o indivíduo desenvolva suas atividades ocupacionais e sociais, obtendo uma melhor qualidade de vida. 


\section{OBJETIVOS}


Avaliar a percepção dos portadores de IRC com relação ao cotidiano, e ao seu funcionamento ocupacional, em dois serviços públicos de saúde: UTR do HC de Ribeirão Preto - HCRP e no SENERP.

Avaliar a percepção dessas pessoas com relação a sua qualidade de vida dentro dos seguintes domínios: Físico, Psicológico, Relações Sociais e Meio Ambiente. 


\section{MATERIAIS E MÉTODOS}




\subsection{Aspectos Éticos}

O projeto foi apreciado e aprovado pelo Comitê de Ética em Pesquisa do HC de Ribeirão Preto e da Faculdade de Medicina de Ribeirão Preto-USP, de acordo

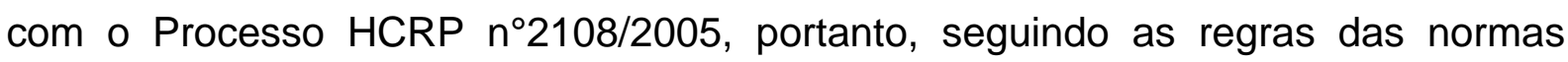
éticas em pesquisa com humanos (ANEXO A). Foi solicitado o consentimento escrito dos sujeitos (ANEXO B), sendo esclarecido que a participação seria voluntária e com possibilidade de desistência.

\subsection{Desenho do Estudo e Período}

Trata-se de um estudo quantitativo transversal do tipo analítico-descritivo.

\subsection{Casuística, população e amostra}

A população foi composta por pacientes que fazem o tratamento em HD na UTR do HCRP e no SENERP, apresentando uma amostra de 70 pacientes.

O tamanho da amostra foi suficiente para os eventuais cruzamentos das variáveis relevantes, dentro das possibilidades determinadas pela disponibilidade e tempo do pesquisador.

É importante lembrar que no SENERP foram entrevistados pacientes com a intenção de se completar a amostra $n=70$. Não se buscou a comparação entre os serviços e não teve-se como objetivo que a amostra fosse proporcional e 
representativa dos mesmos. O recrutamento no SENERP foi realizado por sorteio, através da lista de pacientes agendados para cada dia de trabalho do pesquisador.

\subsection{Critérios de Inclusão:}

Em ambos os serviços: ser paciente com IRC em tratamento de HD, com idades entre 15 e 60 anos e aptos a responder aos questionários.

\subsection{Critérios de Exclusão}

Pacientes fora da idade delimitada, todos aqueles que não apresentaram condições de compreender os questionários e aqueles com presença de outra doença mais comprometedora que a IRC.

\subsection{Local:}

Os dados foram coletados na UTR do HCRP e no SENERP.

\subsubsection{Caracterização da UTR}

A UTR - setor HD pertence ao HCRP. Trata-se de um Hospital de nível 
terciário (serviço de retaguarda do SUS) que atende pacientes de Ribeirão Preto e região com doenças complexas e que não puderam ser resolvidas nas UBS, Unidades Básicas de Saúde.

O HCRP proporciona assistência à saúde em nível ambulatorial e hospitalar, que compreende cuidados de prevenção, de tratamento e recuperação de natureza clínica e /ou cirúrgica, serviços complementares de diagnósticos e tratamentos nas mais diversas especialidades médicas.

A UTR Apresenta em torno de 33 pacientes divididos em três turnos. A unidade é dividida em duas salas, sendo uma para pacientes com hepatite B (com duas máquinas, uma para cada paciente) e outra para sorologias negativas (com quatro máquinas). O local também possui enfermaria para recém transplantados e com complicações. A equipe é composta por enfermeiros, psicólogo, assistente social, médicos contratados e residentes e nutricionista.

\subsubsection{Caracterização do SENERP}

O serviço atende a conveniados e a usuários do SUS (para a pesquisa, participaram apenas os do SUS) em HD, diálise peritoneal e transplantados. Havia em torno de 237 pacientes em HD.

A equipe é composta por um diretor clínico e um diretor administrativo, 6 médicos residentes, 4 enfermeiras, auxiliares e técnicos de enfermagem, assistente social, psicólogo e nutricionista.

Além dos serviços de diálise, há os consultórios e a maioria dos pacientes atendidos são pelo SUS, provenientes também do município de Ribeirão Preto e 
região, divididos em três turnos.

\subsection{Instrumentos}

O questionário para a caracterização sócio demográfico foi elaborado pela própria pesquisadora e seu orientador. Trata-se de um questionário com 15 perguntas relativas a idade, sexo, tipo de união, escolaridade, renda individual, familiar, transporte e cidade em que reside, e perguntas clinicas como: tempo que está em HD e se há associação a outras doenças.

O SAOF (Self Assesment of Occupational Functioning), auto-avaliação do funcionamento ocupacional, foi desenvolvido pelas autoras Baron e Curtin ${ }^{6}$ (1990 apud TEDESCO, 2000), do Departamento de Terapia Ocupacional da Universidade de Illinois, Chicago, com validação recente, no Brasil em 2.000. O instrumento pode ser utilizado com pessoas entre 14 e 85 anos e apresenta como principal objetivo identificar a percepção do próprio paciente em relação a seu funcionamento ocupacional, incluindo a compreensão de suas forças, áreas de adequação e limitações. Conforme relata Morais (2004), o questionário oferece subsídios para avaliar o engajamento do indivíduo no seu dia-a-dia e em ocupações relacionadas à sua auto-organização diária, como as necessidades de manutenção, produção e lazer.

É importante relatar que a base teórica do SAOF é o modelo da ocupação humana. Para Kielhofner e Barret (2002) este modelo fornece uma maneira de

\footnotetext{
${ }^{6}$ BARON, K.B.; CURTIN, C. The Self Assesment of Occupational Functioning (SAOF). Department of Occupational Therapy. University of Illinois, Chicago,1990.
} 
pensar sobre comportamento ocupacional de uma pessoa e a sua disfunção ocupacional. Seus conceitos envolvem a motivação para a ocupação, com padrões de rotina do comportamento ocupacional, com a natureza do desempenho trabalhado e com a influência do Meio Ambiente na ocupação. O modelo oferece um amplo esquema de trabalho para obtenção de dados sobre um cliente, para o entendimento sobre os pontos fortes e fracos desse cliente e para selecionar e implementar um plano de terapia.

O SAOF apresenta um formulário de aplicação que abrange 23 questões, cobrindo sete áreas de conteúdo: causalidade pessoal, valores, interesses, papéis, hábitos, habilidades e Meio Ambiente. Para isso, utiliza-se de uma escala de três pontos de classificação: ponto forte, adequada e necessidade de melhora que quantifica a percepção do paciente sobre as áreas de funcionamento ocupacional, onde seu desempenho é avaliado como: muito bom (forte) bom (adequado) e presença de dificuldades (necessidade de melhora) (TEDESCO, 2000).

O último instrumento utilizado é o desenvolvido pelo grupo de qualidade de vida da Organização Mundial de Saúde (WHOQOL - World Health Organization Quality of Life Group), sendo uma versão abreviada do WHOQOL-100, o WHOQOLbref. Este instrumento contém 26 questões, tendo 24divididas em quatro domínios: Físico, Psicológico, Relações Sociais e Meio Ambiente e duas questões gerais de qualidade de vida. Assim, diferente do WHOQOL-100, em que cada uma das 24 facetas é avaliada a partir de quatro questões, no WHOQOL-bref cada faceta é avaliada a partir de uma questão. Os dados que deram origem à versão abreviada foram extraídas do texto de campo de 20 centros em 18 países diferentes (FLECK et al., 2000). 


\subsection{Procedimentos}

\subsection{1- Estudo Piloto}

Foi realizado um estudo preliminar com 10 sujeitos de ambos os sexos com idade entre 15 e 70 anos, sendo cinco de cada serviço (UTR e SENERP), aos quais foram aplicados o questionário sócio-demográfico, o WHOQO-bref para avaliação da qualidade de vida e o questionário de auto-avaliação do funcionamento ocupacional SAOF. É necessário lembrar que esses questionários foram excluídos da amostra definitiva. A aplicação dos questionários foi individual e auto-aplicável (houve um caso em que a pessoa não era alfabetizada e o questionário foi respondido com o auxílio da pesquisadora). Com base nas dificuldades mostradas, como dificuldade de compreensão por algumas pessoas, decidiu-se, para a coleta de dados, que todos os questionários seriam aplicados pela própria pesquisadora, mesmo para os alfabetizados, com boa compreensão. O limite da idade, que até o presente momento estava indefinido, foi delimitado em até 60 anos.

\subsection{2- Coleta de dados}

Foram coletados primeiramente de todos os pacientes da UTR, que estavam dentro dos critérios de inclusão, sendo 16 pacientes que, somados aos 54 do SENERP, totalizaram 70 pacientes, com idade entre 17 e 60 anos. As entrevistas do SENERP foram realizadas por sorteio, considerando os que estavam agendados 
naquele dia e horário e que também fizessem parte dos critérios de inclusão. A pesquisa foi realizada no período de 14 de junho a 27 de setembro de 2005 e os instrumentos foram utilizados individualmente pela pesquisadora, dentro da seguinte ordem de aplicação:

- Questionário sócio-demográfico (ANEXO C) com perguntas como: idade, sexo, tipo de união, escolaridade, renda individual, familiar, transporte e cidade em que reside. E perguntas clínicas como: o tempo em que está em HD e associação a outra doença;

- Auto-avaliação do funcionamento ocupacional (SAOF) (ANEXO D) (TEDESCO, 2000);

- Instrumento de Avaliação de Qualidade de Vida da Organização Mundial da Saúde (WHOQOL-bref) (ANEXO E) (FLECK, 1998).

\section{9 - Análise dos Dados.}

Após o devido processamento, os resultados foram organizados em tabelas e cruzados em duas variáveis quando adequado. Para facilitar as análises, foram utilizadas porcentagens e médias segundo a conveniência da apresentação.

$\mathrm{Na}$ comparação dos escores dos grupos foram utilizados testes não paramétricos que são os testes adequados para este tipo de análise. Assim, utilizouse a prova $U$ de Mann-Whitney para a comparação dos escores de dois grupos, ou a prova de Kruskal-Wallis para a comparação simultânea de mais de dois grupos (HOLLANDER \& WOLF, 1999). Todos os testes foram realizados sob a admissão de probabilidade de erro de primeira espécie (alfa) de 5\%, e do tipo mono-caudal para as provas de Mann-Whitney ou bi-caudal para as demais. 
IV. RESULTADOS 


\subsection{Caracterização do perfil sócio-demográfico}

Tabela 1 - Caracterização do grupo etário em relação ao sexo.

\begin{tabular}{lccc}
\hline & \multicolumn{2}{c}{ Sexo } & \multirow{2}{*}{ Total } \\
\cline { 2 - 3 } Grupo Etário & Masculino & Feminino & $\mathbf{n}$ \\
& $\mathbf{n}$ & $\mathbf{n}$ & $\%$ \\
\hline \multirow{2}{*}{ Até $\mathbf{4 0}$} & 14 & 9 & 23 \\
& 40.00 & 25.71 & 32.86 \\
$\mathbf{4 0} \mathbf{a} \mathbf{4 9}$ & 10 & 14 & 24 \\
& 28.57 & 40.00 & 34.29 \\
$\mathbf{5 0} \mathbf{~ +}$ & 11 & 12 & 23 \\
& 31.43 & 34.29 & 32.86 \\
Total & 35 & 35 & 70 \\
& 100.00 & 100.00 & 100.00 \\
\hline
\end{tabular}

Legenda : $\mathrm{n}$ - Quantidade de pacientes.

A Tabela 1 relaciona o sexo ao grupo etário, onde se observa que há um equilíbrio na participação em ambos os sexos, com 35 de cada sexo totalizando a amostra $n=70$.. No grupo etário até os 40 anos, o número de participantes masculino é maior que o feminino, já no de 40 a 49 e 50 ou mais, o número feminino é maior.

Tabela 2 - Caracterização do grupo etário em relação ao local.

\begin{tabular}{|c|c|c|c|}
\hline \multirow[b]{2}{*}{ Grupo Etário } & \multicolumn{2}{|c|}{ Local } & \multirow[b]{2}{*}{$\begin{array}{c}\text { Total } \\
\mathbf{n} \\
\%\end{array}$} \\
\hline & $\begin{array}{c}\text { UTR-HC } \\
\mathbf{n} \\
\% \\
\end{array}$ & $\begin{array}{c}\text { SENERP } \\
\mathbf{n} \\
\% \\
\end{array}$ & \\
\hline Até 40 & $\begin{array}{c}6 \\
37,50\end{array}$ & $\begin{array}{c}17 \\
31.48\end{array}$ & $\begin{array}{c}23 \\
32.86\end{array}$ \\
\hline 40 a 49 & $\begin{array}{c}8 \\
50.00\end{array}$ & $\begin{array}{c}16 \\
29.63\end{array}$ & $\begin{array}{c}24 \\
34.29\end{array}$ \\
\hline $50 \mathrm{e}+$ & $\begin{array}{c}2 \\
12.50\end{array}$ & $\begin{array}{c}21 \\
38.89\end{array}$ & $\begin{array}{c}23 \\
32.86\end{array}$ \\
\hline Total & $\begin{array}{c}16 \\
100.00 \\
\end{array}$ & $\begin{array}{c}54 \\
100.00 \\
\end{array}$ & $\begin{array}{c}70 \\
100.00\end{array}$ \\
\hline
\end{tabular}


Observa-se que o maior número de participantes em relação ao grupo etário é do SENERP.

Tabela 3 - Caracterização do sexo em relação ao local.

\begin{tabular}{|c|c|c|c|}
\hline \multirow[b]{2}{*}{ Sexo } & \multicolumn{2}{|c|}{ Local } & \multirow[b]{2}{*}{$\begin{array}{c}\text { Total } \\
\mathbf{n} \\
\%\end{array}$} \\
\hline & $\begin{array}{c}\text { UTR-HC } \\
\mathbf{n} \\
\%\end{array}$ & $\begin{array}{c}\text { SENERP } \\
\mathbf{n} \\
\%\end{array}$ & \\
\hline Masculino & $\begin{array}{c}9 \\
56.25\end{array}$ & $\begin{array}{c}26 \\
48.15\end{array}$ & $\begin{array}{c}35 \\
50.00\end{array}$ \\
\hline Feminino & $\begin{array}{c}7 \\
43.75\end{array}$ & $\begin{array}{c}28 \\
51.85\end{array}$ & $\begin{array}{c}35 \\
50.00\end{array}$ \\
\hline Total & $\begin{array}{c}16 \\
100.00 \\
\end{array}$ & $\begin{array}{c}54 \\
100.00 \\
\end{array}$ & $\begin{array}{c}70 \\
100.00 \\
\end{array}$ \\
\hline
\end{tabular}

A Tabela 3 mostra que o número de participantes masculino do $\mathrm{HC}$ foi superior ao feminino, já no SENERP o número de participantes do sexo feminino foi maior.

Tabela 4 - Caracterização do local de residência em relação ao meio de transporte.

\begin{tabular}{|c|c|c|c|}
\hline \multirow[b]{2}{*}{$\begin{array}{l}\text { Local de } \\
\text { Residência }\end{array}$} & \multicolumn{2}{|c|}{ Local } & \multirow[b]{2}{*}{$\begin{array}{c}\text { Total } \\
\mathbf{n} \\
\%\end{array}$} \\
\hline & $\begin{array}{c}\text { Próprio } \\
\text { n } \\
\%\end{array}$ & $\begin{array}{c}\text { Outro } \\
\mathbf{n} \\
\% \\
\end{array}$ & \\
\hline Rib. Preto & $\begin{array}{c}16 \\
36.36\end{array}$ & $\begin{array}{c}28 \\
63.64\end{array}$ & $\begin{array}{c}44 \\
100.00\end{array}$ \\
\hline Outro Local & $\begin{array}{c}1 \\
3.85\end{array}$ & $\begin{array}{c}25 \\
96.15\end{array}$ & $\begin{array}{c}26 \\
100.00\end{array}$ \\
\hline Total & $\begin{array}{c}17 \\
24.29\end{array}$ & $\begin{array}{c}53 \\
75.71 \\
\end{array}$ & $\begin{array}{c}70 \\
100.00 \\
\end{array}$ \\
\hline
\end{tabular}

Legenda : $\mathrm{n}$ - Quantidade de pacientes. 
Na Tabela 4, observa-se que a maioria dos participantes reside em Ribeirão Preto e não tem meio de transporte próprio, assim como os participantes de outro local, os outros meios de transporte utilizados eram ônibus, ambulância, leva-e-traz.

Tabela 5 - Caracterização do estado civil.

\begin{tabular}{lccc}
\hline & \multicolumn{2}{c}{ Sexo } & Total \\
\cline { 2 - 3 } Tem Cônjuge & Masculino & Feminino & $\mathbf{n}$ \\
& $\mathbf{n}$ & $\mathbf{n}$ & $\%$ \\
\hline \multirow{2}{*}{ NÃO } & 12 & 19 & 31 \\
& 38.71 & 61.29 & 100.00 \\
SIM & 23 & 16 & 39 \\
& 58.97 & 41.03 & 100.00 \\
Total & 35 & 35 & 70 \\
& 50.00 & 50.00 & 100.00 \\
\hline
\end{tabular}

Legenda : $\mathrm{n}-$ Quantidade de pacientes.

Nesta tabela, observa-se que a maioria tem cônjuge, tanto no sexo masculino como no feminino.

Tabela 6 - Caracterização dos anos de estudo em relação ao grupo de renda.

\begin{tabular}{|c|c|c|c|}
\hline \multirow[b]{2}{*}{$\begin{array}{c}\text { Anos de } \\
\text { Estudo }\end{array}$} & \multicolumn{2}{|c|}{ Grupo de Renda } & \multirow[b]{2}{*}{$\begin{array}{c}\text { Total } \\
\mathbf{n} \\
\%\end{array}$} \\
\hline & $\begin{array}{c}\text { Até } 300 \\
\mathbf{n} \\
\%\end{array}$ & $\begin{array}{c}\text { Acima de } 1050 \\
\text { n } \\
\%\end{array}$ & \\
\hline Até 4 & $\begin{array}{c}13 \\
56.52\end{array}$ & $\begin{array}{c}10 \\
43.48\end{array}$ & $\begin{array}{c}23 \\
100.00\end{array}$ \\
\hline 5 a 8 & $\begin{array}{c}12 \\
41.38\end{array}$ & $\begin{array}{c}17 \\
58.62\end{array}$ & $\begin{array}{c}29 \\
100.00\end{array}$ \\
\hline $9 \mathrm{e}+$ & $\begin{array}{c}4 \\
25.00\end{array}$ & $\begin{array}{c}12 \\
75.00\end{array}$ & $\begin{array}{c}16 \\
100.00\end{array}$ \\
\hline Total & $\begin{array}{c}29 \\
42.65\end{array}$ & $\begin{array}{c}39 \\
57.35\end{array}$ & $\begin{array}{c}68 \\
100.00\end{array}$ \\
\hline
\end{tabular}

Legenda : $\mathrm{n}-$ Quantidade de pacientes. 
de estudo e recebe renda acima de 1.050 reais. Participantes com 9 ou mais anos de estudo já tiveram menor participação e também recebem renda superior a 1.050. Até 4 anos de estudo são os que mais recebem renda de 300 reais. É importante ressaltar que nas Tabelas 6 e 7, o valor total é 68 porque dois pacientes se recusaram a responder sobre a renda.

Tabela 7 - Caracterização do grupo de renda em relação ao desempenho de atividade.

\begin{tabular}{lccc}
\hline & \multicolumn{2}{c}{$\begin{array}{c}\text { Desempenha Atividade } \\
\text { Grupo de }\end{array}$ (artesanal, esporte, outro) } & Total \\
\cline { 2 - 3 } Renda & $\mathbf{N a ̃ o}$ & Sim & $\mathbf{n}$ \\
& $\mathbf{n}$ & $\mathbf{n}$ & $\%$ \\
\hline \multirow{2}{*}{ Até 300} & $\%$ & $\%$ & \\
& 11 & 18 & 29 \\
Acima de 300 & 37.93 & 62.97 & 100.00 \\
Total & 9 & 30 & 39 \\
& 23.08 & 76.92 & 100.00 \\
& 20 & 48 & 68 \\
\hline
\end{tabular}

Legenda : $n$ - Quantidade de pacientes.

A Tabela 7 mostra que as pessoas com renda acima de 300 reais são as que mais desempenham alguma atividade.

Tabela 8 - Caracterização do tempo em anos de HD em relação ao local.

\begin{tabular}{|c|c|c|c|}
\hline \multirow[b]{2}{*}{$\begin{array}{c}\text { Tempo em } \\
\text { anos }\end{array}$} & \multicolumn{2}{|c|}{ Local } & \multirow[b]{2}{*}{$\begin{array}{c}\text { Total } \\
\mathbf{n} \\
\%\end{array}$} \\
\hline & $\begin{array}{c}\text { UTR-HC } \\
\mathbf{n} \\
\%\end{array}$ & $\begin{array}{c}\text { SENERP } \\
\mathbf{n} \\
\%\end{array}$ & \\
\hline Até 3 anos & $\begin{array}{c}5 \\
31.25\end{array}$ & $\begin{array}{c}26 \\
48.15\end{array}$ & $\begin{array}{c}31 \\
44.29\end{array}$ \\
\hline Mais de 3 & $\begin{array}{c}11 \\
68.75\end{array}$ & $\begin{array}{c}28 \\
51.85\end{array}$ & $\begin{array}{c}39 \\
55.71\end{array}$ \\
\hline Total & $\begin{array}{c}16 \\
100.00\end{array}$ & $\begin{array}{c}54 \\
100.00\end{array}$ & $\begin{array}{c}70 \\
100.00\end{array}$ \\
\hline
\end{tabular}


Observa-se que a maioria dos participantes faz HD há mais de 3 anos $(55,7 \%)$ e é do SENERP $(51,85 \%)$, totalizando um número de 28 pacientes.

Tabela 9 - Caracterização do tempo em anos em relação ao auxilio de pessoas.

\begin{tabular}{cccc}
\hline \multirow{2}{*}{ Tempo em } & \multicolumn{2}{c}{ Auxilio de Pessoas } & Total \\
\cline { 2 - 3 } anos & Não & Sim & $\mathbf{n}$ \\
& $\mathbf{n}$ & $\mathbf{n}$ & $\%$ \\
\hline \multirow{2}{*}{ Menos de $\mathbf{1}$} & 14 & $\%$ & 31 \\
& 42.42 & 45,95 & 44.29 \\
$\mathbf{1} \mathbf{+}$ & 19 & 20 & 39 \\
& 57.58 & 54.05 & 55.71 \\
Total & 33 & 37 & 70 \\
& 100.00 & 100.00 & 100.00 \\
\hline
\end{tabular}

Legenda : $\mathrm{n}-$ Quantidade de pacientes.

A maioria das pessoas deste estudo que faz HD há mais de 3 anos (veja a Tabela 8 e a Tabela 9), são as que mais necessitam do auxílio de outras pessoas para realizarem as tarefas de seu cotidiano. Ao todo, são 37 pessoas. 


\subsection{Avaliação do questionário SAOF}

Tabela 10 - Médias e desvios-padrão das respostas individuais obtidas na aplicação do Questionário SAOF, segundo cada área de referência.

\begin{tabular}{lcccccc}
\hline \multirow{2}{*}{ Áreas } & \multicolumn{3}{c}{ Médias } & \multicolumn{3}{c}{ Desvios Padrão } \\
\cline { 2 - 7 } & $\begin{array}{c}\text { Ponto } \\
\text { Forte }\end{array}$ & Adequada & $\begin{array}{c}\text { Necessita } \\
\text { melhorar }\end{array}$ & $\begin{array}{c}\text { Ponto } \\
\text { Forte }\end{array}$ & Adequada & $\begin{array}{c}\text { Necessita } \\
\text { melhorar }\end{array}$ \\
\hline 1- Causalidade pessoal & 60,5 & 24,3 & 15,2 & 35,6 & 30,5 & 25,8 \\
2 - Valores & 56,7 & 22,8 & 20,5 & 34,2 & 26,9 & 27,4 \\
3 - Interesses & 60 & 32,4 & 7,7 & 38,3 & 36,3 & 20,6 \\
4- Papéis & 62,8 & 29,00 & 8,1 & 31,4 & 31,0 & 17,4 \\
5- Hábitos & 46,2 & 33,8 & 20 & 36,0 & 35,2 & 26,8 \\
6- Habilidades & 57,7 & 27,1 & 15,1 & 28,7 & 25,3 & 18,0 \\
7- Meio Ambiente & 74,3 & 20 & 5,7 & 44,0 & 40,3 & 23,4 \\
\hline
\end{tabular}

Observa-se que em todas as áreas o "Ponto Forte" foi a opção com maior escolha. A área denominada de Meio Ambiente apresentou a média de 74,3\%, sendo a maior. A menor média, $46,2 \%$, foi a referente à área 5 (Hábitos), ainda considerando a alternativa Ponto Forte. As áreas com maior dificuldade foram a 2 $(20,5 \%)$ e a $5(20 \%)$.

\subsection{Avaliação do questionário WHOQOL-bref}

Tabela 11 - Média dos escores da escala WHOQOL-bref - domínio Físico por idade e sexo.

\begin{tabular}{lccc}
\hline \multicolumn{1}{c}{$\begin{array}{c}\text { Grupo } \\
\text { Etário }\end{array}$} & \multicolumn{2}{c}{ Sexo } & \multirow{2}{*}{ Total } \\
\cline { 2 - 3 } & Masculino & Feminino & \\
\hline & & & \\
Até 40 & 55.1 & 59.1 & 56.7 \\
$40 \mathrm{a} 49$ & 48.6 & 64.5 & 57.9 \\
$50 \mathrm{e}+$ & 52.3 & 63.7 & 58.2 \\
Total & 52.3 & 62.9 & 57.6 \\
\hline
\end{tabular}


A Tabela 11 mostra a média dos escores do domínio Físico relacionados a idade e sexo, em que se observa que o grupo etário com 50 anos ou mais tem tendência a apresentar um maior escore $(58,2)$ e o que pode indicar menor escore é para a faixa etária de até 40 anos $(56,7)$. Observa-se também que os escores do sexo feminino apresenta no total 62,9 , indicando ser um escore maior que 0 masculino 52,3.

Tabela 12 - Média dos escores da escala WHOQOL-bref domínio Psicológico por idade e sexo.

\begin{tabular}{lccc}
\hline \multicolumn{1}{c}{$\begin{array}{c}\text { Grupo } \\
\text { Etário }\end{array}$} & \multicolumn{2}{c}{ Sexo } & \multirow{2}{*}{ Total } \\
\cline { 2 - 3 } Masculino & Feminino & \\
\hline Ate 40 & 64.3 & 64.4 & 64.3 \\
40 a 49 & 66.3 & 70.8 & 68.9 \\
50 e + & 70.8 & 68.1 & 69.4 \\
Total & 66.9 & 68.2 & 67.6 \\
\hline
\end{tabular}

Em relação ao domínio Psicológico, o sexo feminino tem tendência a apresentar um escore maior $(68,2)$ sendo que a faixa etária que indicou escore maior foi a de 50 anos e mais $(69,4)$ e a que indicou escore menor foi a de até 40 anos $(64,4)$.

Tabela 13 - Média dos escores da escala WHOQOL-bref domínio Relações Sociais por idade e sexo:

\begin{tabular}{cccc}
\hline Grupo & \multicolumn{2}{c}{ Sexo } & \multirow{2}{*}{ Total } \\
\cline { 2 - 3 } Etário & Masculino & Feminino & \\
\hline Até 40 & 64.9 & 66.7 & 65.6 \\
40 a 49 & 73.3 & 79.2 & 76.7 \\
50 e + & 64.4 & 67.4 & 65.9 \\
Total & 67.1 & 71.9 & 69.5 \\
\hline
\end{tabular}


Observa-se nesta tabela que a faixa etária dos 40 aos 49 anos tem a tendência a apresentar média de escore maior $(76,7)$ e a que indica menor é até os 40 , sendo que novamente o sexo feminino indicou escore maior.

Tabela 14 - Média dos escores da escala WHOQOL-bref domínio Meio Ambiente: por idade e sexo.

\begin{tabular}{cccc}
\hline Grupo & \multicolumn{2}{c}{ Sexo } & \multirow{2}{*}{ Total } \\
\cline { 2 - 3 } Etário & Masculino & Feminino & \\
\hline Ate 40 & 59.8 & 60.1 & 59.9 \\
40 a 49 & 64.1 & 66.1 & 65.2 \\
50 e + & 64.8 & 69.8 & 67.4 \\
Total & 62.6 & 65.8 & 64.2 \\
\hline
\end{tabular}

Nessa tabela, a faixa etária dos 50 anos e mais indicou média de escore maior $(67,4)$ e a de menor tendência foi a faixa etária até os 40 anos. O sexo feminino também apresentou média maior em relação ao masculino.

Tabela 15 - Média dos escores da escala WHOQOL-bref domínio Saúde em Geral, por idade e sexo.

\begin{tabular}{cccc}
\hline Grupo & \multicolumn{2}{c}{ Sexo } & \multirow{2}{*}{ Total } \\
\cline { 2 - 3 } Etário & Masculino & Feminino & \\
\hline Ate 40 & 60.7 & 56.9 & 59.2 \\
40 a 49 & 53.8 & 67.9 & 62.0 \\
50 e + & 60.2 & 60.4 & 60.3 \\
Total & 58.6 & 62.5 & 60.5 \\
\hline
\end{tabular}

Observa-se que a média que tem tendência ao maior escore é para a faixa etária dos 40 aos 49 anos e a que indica menor média de escore é até os 40 anos $(59,2)$, sendo que o sexo feminino apresentou média maior $(62,5)$. 
Tabela 16 - Média dos escores da escala WHOQOL-bref em cada domínio, segundo condição marital.

\begin{tabular}{lccccc}
\hline $\begin{array}{c}\text { Tem } \\
\text { Cônjuge }\end{array}$ & $\begin{array}{c}\text { Média } \\
\text { (Físico) }\end{array}$ & $\begin{array}{c}\text { Média } \\
\text { (Psico) }\end{array}$ & $\begin{array}{c}\text { Média } \\
\text { (Social) }\end{array}$ & $\begin{array}{c}\text { Média } \\
\text { (Ambiente) }\end{array}$ & $\begin{array}{c}\text { Média } \\
\text { (Saúde Geral) }\end{array}$ \\
\hline NÃO & 61.4 & 68.7 & 71.5 & 63.9 & 61.7 \\
SIM & 54.6 & 66.7 & 67.9 & 64.4 & 59.6 \\
Total & 57.6 & 67.6 & 69.5 & 64.2 & 60.5 \\
\hline
\end{tabular}

Em relação à condição marital, observa-se que quem tem tendência a apresentar média maior é quem não tem cônjuge $(61,7)$ indicando também maior média no domínio Relações Sociais $(71,5)$ e menor média no domínio Físico $(61,4)$. Quem tem cônjuge indicou média Saúde Geral de 59,6, com média no domínio Relação Social de 67,9 e domínio Físico de 54,6.

Tabela 17 - Média dos escores da escala WHOQOL-bref, segundo quantidade de pessoas na residência.

\begin{tabular}{lccccc}
\hline $\begin{array}{c}\text { Pessoas na } \\
\text { Residência }\end{array}$ & $\begin{array}{c}\text { Média } \\
\text { (Físico) }\end{array}$ & $\begin{array}{c}\text { Média } \\
\text { (Psico) }\end{array}$ & $\begin{array}{c}\text { Média } \\
\text { (Social) }\end{array}$ & $\begin{array}{c}\text { Média } \\
\text { (Ambiente) }\end{array}$ & $\begin{array}{c}\text { Média } \\
\text { (Saúde Geral) }\end{array}$ \\
\hline 1 e 2 & 61.7 & 69.7 & 69.4 & 66.8 & 63.2 \\
3 e 4 & 55.2 & 65.6 & 68.8 & 60.6 & 60.5 \\
5 e + & 57.7 & 68.8 & 70.8 & 67.5 & 58.1 \\
Total & 57.6 & 67.6 & 69.5 & 64.2 & 60.5 \\
\hline
\end{tabular}

Nessa tabela, observa-se que as residências com menor quantidade de pessoas (de uma a duas), são as que têm tendência a apresentar média com escore maior $(63,2)$ para o domínio de Saúde em Geral e as com 5 ou mais pessoas são as que indicam menor média de escore $(58,1)$. 
Tabela 18 - Média dos escores da escala WHOQOL-bref, segundo os anos de estudo.

\begin{tabular}{lccccc}
\hline $\begin{array}{c}\text { Anos de } \\
\text { Estudo }\end{array}$ & $\begin{array}{c}\text { Média } \\
\text { (Físico) }\end{array}$ & $\begin{array}{c}\text { Média } \\
\text { (Psico) }\end{array}$ & $\begin{array}{c}\text { Média } \\
\text { (Social) }\end{array}$ & $\begin{array}{c}\text { Média } \\
\text { (Ambiente) }\end{array}$ & $\begin{array}{c}\text { Média } \\
\text { (Saúde Geral) }\end{array}$ \\
\hline Ate 4 & 55.1 & 64.5 & 61.0 & 61.1 & 54.5 \\
5 a 8 & 55.9 & 67.4 & 74.1 & 63.1 & 61.2 \\
9 e + & 64.5 & 72.7 & 74.5 & 70.9 & 68.8 \\
Total & 57.6 & 67.7 & 69.5 & 64.2 & 60.5 \\
\hline
\end{tabular}

As pessoas com 9 anos ou mais de estudo são as que indicam média maior $(68,8)$ em duas questões gerais de saúde presentes no questionário aplicado e as de até 4 anos indicam média menor $(54,5)$.

Tabela 19 - Média dos escores da escala WHOQOL-bref, em cada domínio, segundo o tempo em anos de HD.

\begin{tabular}{lccccc}
\hline $\begin{array}{c}\text { Tempo } \\
\text { em Anos }\end{array}$ & $\begin{array}{c}\text { Média } \\
\text { (Físico) }\end{array}$ & $\begin{array}{c}\text { Média } \\
\text { (Psico) }\end{array}$ & $\begin{array}{c}\text { Média } \\
\text { (Social) }\end{array}$ & $\begin{array}{c}\text { Média } \\
\text { (Ambiente) }\end{array}$ & $\begin{array}{c}\text { Média } \\
\text { (Saúde Geral) }\end{array}$ \\
\hline & & & & & \\
Até 3 anos & 57.8 & 67.2 & 69.4 & 67.2 & 62.5 \\
Mais de 3 & 57. & 67.8 & 69.7 & 61.8 & 59.0 \\
Total & 57.6 & 67.6 & 69.5 & 64.2 & 60.5 \\
\hline
\end{tabular}

As pessoas com até 3 anos de HD indicam média $(62,5)$ em duas questões gerais de saúde e as com mais de 3 anos, de 59,0. Observa-se que o domínio Psicológico até os 3 anos tem tendência a apresentar média de escore menor $(67,2)$ do que os com mais de 3 anos $(67,8)$, assim como ocorre também com o físico. 
Tabela 20 - Média dos escores da escala WHOQOL-bref, em cada domínio, segundo o tempo de HD (1 ano ou mais).

\begin{tabular}{lccccc}
\hline $\begin{array}{c}\text { Tempo de } \\
\text { HD }\end{array}$ & $\begin{array}{c}\text { Média } \\
\text { (Físico) }\end{array}$ & $\begin{array}{c}\text { Média } \\
\text { (Psico) }\end{array}$ & $\begin{array}{c}\text { Média } \\
\text { (Social) }\end{array}$ & $\begin{array}{c}\text { Média } \\
\text { (Ambiente) }\end{array}$ & $\begin{array}{c}\text { Média } \\
\text { (Saúde Geral) }\end{array}$ \\
\hline \multirow{2}{*}{ Menos de 1 } & 60.6 & 67.9 & 70.8 & 64.1 & 62.8 \\
1 e + & 52.6 & 67.0 & 67.3 & 64.4 & 56.7 \\
Total & 57.6 & 67.6 & 69.5 & 64.2 & 60.5 \\
\hline
\end{tabular}

Observa-se que as pessoas com menos de 1 ano de HD indicam média de 62,8 e as com 1 ano ou mais, 56,7. A avaliação do domínio Físico das pessoas com mais de 1 ano de tratamento é 52,6 e com menos de 1 ano é 60,6.

Tabela 21 - Média dos escores da escala WHOQ OL, em cada domínio, segundo o meio de transporte.

\begin{tabular}{lccccc}
\hline Transporte & $\begin{array}{c}\text { Média } \\
\text { (Físico) }\end{array}$ & $\begin{array}{c}\text { Média } \\
\text { (Psico) }\end{array}$ & $\begin{array}{c}\text { Média } \\
\text { (Social) }\end{array}$ & $\begin{array}{c}\text { Média } \\
\text { (Ambiente) }\end{array}$ & $\begin{array}{c}\text { Média } \\
\text { (Saúde Geral) }\end{array}$ \\
\hline Próprio & 55.5 & 70.1 & 69.1 & 68.6 & 58.1 \\
Outro & 58.3 & 66.7 & 69.7 & 62.8 & 61.3 \\
Total & 57.6 & 67.6 & 69.5 & 64.2 & 60.5 \\
\hline
\end{tabular}

A média de saúde em geral das pessoas que possuem outro meio de transporte é 61,3 e as que possuem próprio é 58,1 . Observa-se que o domínio Psicológico de quem possui veículo próprio indica média de escore maior $(70,1)$ do que outro meio de transporte e o Meio Ambiente e também $(68,6)$. 


\subsection{ESTUDOS COMPARATIVOS}

Tabela 22 - Resultados dos testes de comparação dos escores de qualidade de vida (WHOQOL-bref) - domínio Físico.

\begin{tabular}{|c|c|c|c|}
\hline VARIÁVEIS & TESTE & $\mathbf{P}$ & RESULTADO \\
\hline Idade & Kruskal-Wallis & 0,77 & Não Significante \\
\hline Número Pessoas & Kruskal-Wallis & 0,28 & Não Significante \\
\hline Anos de Instrução & Kruskal-Wallis & 0,10 & Não Significante \\
\hline Cônjuge & Mann-Whitney & 0,04 & $\begin{array}{l}\text { WHOQOL-bref (sem cônjuge) > } \\
\text { WHOQOL-bref (Com cônjuge) }\end{array}$ \\
\hline Tempo de Hemo & Mann-Whitney & 0,02 & $\begin{array}{l}\text { WHOQOL-bref (menos 1) > } \\
\text { WHOQOL-bref (mais de 1) }\end{array}$ \\
\hline Meio de Transporte & Mann-Whitney & 0,46 & Não Significante \\
\hline Sexo & Mann-Whitney & 0,00 & $\begin{array}{c}\text { WHOQOL-bref (fem) > WHOQOL- } \\
\text { bref (masc) }\end{array}$ \\
\hline
\end{tabular}

Observa-se nessa tabela que os resultados obtidos frente ao domínio Físico em relação ao cônjuge foram significativos, ou seja, as pessoas sem cônjuge avaliaram sua qualidade de vida mais favoravelmente do que as com cônjuge e, em relação ao tempo, as pessoas que fazem HD há menos de 1 ano avaliaram sua qualidade de vida mais favoravelmente também que as que fazem há mais de 1 ano, assim como as mulheres apresentam qualidade de vida superior aos homens.

Tabela 23 - Resultados dos testes de comparação dos escores de qualidade de vida (WHOQOL-bref) - domínio Psicológico.

\begin{tabular}{lccc}
\hline \multicolumn{1}{c}{ VARIÁVEIS } & TESTE & P & RESULTADO \\
\hline Idade & Kruskal-Wallis & 0,37 & \\
Número Pessoas & Kruskal-Wallis & 0,78 & \\
Anos de Instrução & Kruskal-Wallis & 0,31 & Não Significante \\
Cônjuge & Mann-Whitney & 0,67 & \\
Tempo de Hemo & Mann-Whitney & 0,85 & \\
Meio de Transporte & Mann-Whitney & 0,32 & \\
Sexo & Mann-/whitney & 0,92 & \\
\hline
\end{tabular}

Nesta tabela observa-se que nenhum resultado foi significativo. 
Tabela 24 - Resultados dos testes de comparação dos escores de qualidade de vida (WHOQOL-bref) - domínio Social.

\begin{tabular}{lccc}
\hline \multicolumn{1}{c}{ VARIÁVEIS } & TESTE & P & RESULTADO \\
\hline Idade & Kruskal-Wallis & 0,06 & Não Significante \\
Número Pessoas & Kruskal-Wallis & 0,97 & Não Significante \\
Anos de Instrução & Kruskal-Wallis & 0,04 & $\begin{array}{c}\text { WHOQOL-bref (mais de 4 anos) } \\
\text { > WHOQOL-bref (menos de 4 } \\
\end{array}$ \\
& & & anos) \\
Cônjuge & Mann-Whitney & 0,40 & Não Significante \\
Tempo de Hemo & Mann-Whitney & 0,32 & Não Significante \\
Meio de Transporte & Mann-Whitney & 0,98 & Não Significante \\
Sexo & Mann-Whitney & 0,23 & Não Significante \\
\hline
\end{tabular}

Esta tabela mostra que somente o item Anos de Instrução obteve resultado significativo, observando-se que as pessoas com mais de quatro anos de estudo avaliaram sua qualidade de vida mais favoravelmente de que as com menos de quatro anos.

Tabela 25 - Resultados dos testes de comparação dos escores de qualidade de vida (WHOQOL-bref) - domínio Meio Ambiente.

\begin{tabular}{lccc}
\hline \multicolumn{1}{c}{ VARIÁVEIS } & TESTE & P & RESULTADO \\
\hline Idade & Kruskal-Wallis & 0,11 & Não Significante \\
Número Pessoas & Kruskal-Wallis & 0,10 & Não Significante \\
Anos de Instrução & Kruskal-Wallis & 0,02 & WHOQOL-bref (9 e mais anos)> \\
& & & WHOQOL-bref (menos de 9 anos) \\
Cônjuge & Mann-Whitney & 0,82 & Não Significante \\
Tempo de Hemo & Mann-Whitney & 0,66 & Não Significante \\
Meio de Transporte & Mann-Whitney & 0,09 & Não Significante \\
Sexo & Mann-Whitney & 0,16 & Não Significante \\
\hline
\end{tabular}

Aqui também observa-se que as pessoas com 9 e mais anos de estudo apresentam maior qualidade de vida de que as com menos de nove anos, em relação ao domínio Meio Ambiente. 
Tabela 26 - Resultados dos testes de comparação dos escores de qualidade de vida (WHOQOL-bref) Geral

\begin{tabular}{llcc}
\hline \multicolumn{1}{c}{ VARIÁVEIS } & TESTE & P & RESULTADO \\
\hline Idade & Kruskal-Wallis & 0,73 & Não Significante \\
Número Pessoas & Kruskal-Wallis & 0,57 & Não Significante \\
Anos de Instrução & Kruskal-Wallis & 0,04 & $\begin{array}{c}\text { WHOQOL-bref (9 e mais anos) > } \\
\text { WHOQOL-bref (5 a 8 anos ) > } \\
\end{array}$ \\
& & & WHOQOL-bref (Até 4 anos) \\
Cônjuge & Mann-Whitney & 0,64 & Não Significante \\
Tempo de Hemo & Mann-Whitney & 0,15 & Não Significante \\
Meio de Transporte & Mann-Whitney & 0,76 & Não Significante \\
Sexo & Mann-Whitney & 0,35 & Não Significante \\
\hline
\end{tabular}

Para finalizar, essa tabela representa os resultados para o domínio Saúde em Geral na qualidade de vida. Observa-se que, em relação a todos os domínios, somente o quesito Anos de Instrução apresentou resultado significativo, sendo que nove e mais anos de estudo apresenta maior qualidade de vida do que cinco a oito anos de estudo que, conseqüentemente, é maior que até quatro anos de estudos. 
V. DISCUSSÃO 
A idéia de estudar esse grupo com essa determinada doença (IRC) surgiu pelo fato das limitações ocorridas, das restrições e das dificuldades comprometendo dessa forma a qualidade de vida dessas pessoas. A maioria das bibliografias utilizadas (BORGES, 2003; MARTINS \& CESARINO, 2005) relatam a ruptura do cotidiano dos IRCs e o quanto o tratamento influencia em sua qualidade de vida.

\subsection{Aspectos sócio-demográficos e clínicos}

A amostra foi composta por homens e mulheres, apresentando um equilíbrio entre ambos, 35 cada um .

Em relação ao sexo, a informação encontrada, segundo a SBN ${ }^{7}$ (1997 apud SESSO, 2002), foi que, em 1.999, 52\% dos pacientes em diálise eram do sexo masculino, 26\% tinham mais de 60 anos de idade e estima-se que havia $2,2 \%$ de pacientes com menos de 18 anos de idade em diálise no país e a menor porcentagem é com a idade igual ou menor a 10 anos.

A faixa etária com maior participação foi a de 40 a 49 anos, a idade considerada produtiva. Isso pode ser comparado aos estudos de Carreira e Marcon (2003), os quais relatam que na sua pesquisa a maioria dos participantes com IRC encontra-se em uma faixa etária produtiva, sendo que mais da metade apresenta menos de 60 anos.

Em relação ao local, observa-se que o maior número de participantes em

\footnotetext{
7 SBN - DEPARTAMENTO DE INFORMÁTICA, biênio 1997-98. Registro Brasileiro de Diálise, 1997. Disponível em <http://www.epm.br/medicina/registro/97/rghd97.htm>.
} 
relação ao grupo etário é do SENERP, pois, conforme foi apresentado inicialmente, esse serviço apresenta em torno de 237 pacientes em HD.

Ainda em relação ao sexo, o número de participantes masculinos do $\mathrm{HC}$ foi superior ao feminino.Jjá no SENERP, o número de participantes do sexo feminino foi maior.

A maioria dos participantes reside em Ribeirão Preto e não tem meio de transporte próprio, assim como os outros participantes de outro local. A partir daí podemos observar uma das dificuldades apresentadas pelo insuficiente renal crônico, pois além de enfrentar 4 horas na máquina de HD, sentindo muitas vezes fraqueza e mal estar, a maioria retorna a sua residência de ônibus, muitas vezes prejudicando o tratamento como foi relatado por alguns dos pacientes durante a coleta de dados dessa pesquisa, sendo essa uma informação complementar.

Podemos relatar a condição sócio-econômica dos IRCs, pois, em relação à escolaridade, observa-se que a maioria dos participantes teve de 5 a 8 anos de estudos e recebe renda acima de 1.050 reais. Assim como as com até 9 anos e mais de estudos, que apresentam porcentagem maior (75\%), com renda de 1.050 reais. As pessoas que tiveram até 4 anos de estudo são as que mais recebem renda de até 300,00 reais, sendo essas características comuns nos serviços públicos de saúde.

Carreira e Marcon (2003), em seus estudos, relatam que a maioria dos IRCs não desenvolve atividades remuneradas, porém, quando consegue, necessita muitas vezes da compreensão do patrão e da família. Ainda nos estudos desses autores, a maioria dos familiares queixa-se da taxa de remuneração recebida pelos pacientes, relatando tal fato estar relacionado à função que exercem (trabalhador em fábricas, vendedor ambulante, empregada doméstica) e da taxa de remuneração 
dos aposentados do nosso país.

Outro fator citado por Carreira e Marcon (2003) é que a atividade laboral no cotidiano dos portadores de IRC, conseqüentemente no de sua família, é uma questão extremamente importante a ser abordada pelos profissionais de saúde, considerando que essa doença se manifesta em todas as faixas etárias, principalmente na fase produtiva da vida dessas pessoas, como se observa nesse trabalho.

A baixa renda influencia também na qualidade de aderência ao tratamento, tendo como exemplo a alimentação, pois é muito comum o fato de o paciente que também é diabético, apesar das restrições existentes, continuar alimentando-se com carboidratos por ser mais acessível economicamente (CARREIRA E MARCON, 2003).

Ainda em relação a esses estudos, ocorre a diminuição de passeios e atividades de lazer decorrentes não apenas de horários e medicamentos, mas sim da diminuição da renda, uma vez que há muitos gastos com os medicamentos. A maioria das pessoas com renda acima de 300 reais são as que mais desempenham alguma atividade, comprovando que, além da motivação e interesse, também é necessário uma melhor condição financeira.

Martins e Cesarino (2005) também citam em suas pesquisas as atividades recreativas como sendo uma das mais comprometidas.

A maioria dos participantes faz HD há mais de 3 anos (55,7\%) e são do SENERP $(51,85 \%)$.

As pessoas que fazem HD há mais de 3 anos são as que mais necessitam de auxilio de outras pessoas para realizar as tarefas do seu cotidiano. É necessário lembrar que durante os primeiros meses antes de completar um ano, o auxílio de outras pessoas é bem maior. Com o passar do tempo, elas até necessitam de ajuda, 
mas em proporção menor, ou seja, a pessoa vai adquirindo mais autonomia, principalmente em relação ao auto-cuidado. Muitas pessoas que relataram necessitar de ajuda referiam-se aos afazeres domésticos, acompanhar na HD, mas quanto aos cuidados pessoais apresentavam autonomia.

\subsection{Auto avaliação do funcionamento Ocupacional (SAOF)}

Primeiramente será analisado cada tópico do instrumento.

- Área de causalidade pessoal: a alternativa ponto forte foi uma das mais escolhidas, com porcentagem de $60,5 \%$, onde observa-se que a maioria dos entrevistados acreditam nas suas habilidades e capacidades.

- Área de valores: observa-se que a alternativa necessidade de melhora apresentou uma porcentagem de 20,5\%, e apesar da pequena porcentagem foi onde houve dificuldades dos pacientes com IRC em relação a ter objetivos e expectativas para o seu futuro.

- Área de interesses: não houve dificuldades, apresentando a porcentagem de $60 \%$ na opção ponto forte. Observa-se que mesmo com as limitações, essas pessoas procuram ter interesses em fazer algo.

- Papéis: a maioria consegue desempenhar seus papéis, seja de trabalhador, de estudante, familiar, ou quaisquer que sejam as dificuldades.

- Área de hábitos: observou-se que há dificuldades para essas pessoas em relação a organizar seu tempo, horários, aceitar as mudanças de sua rotina. Nessa área a opção necessidade de melhora apresentou porcentagem de $20 \%$.

- Área de habilidades: a maioria procura ter uma vida social, expressar-se, 
tentar resolver seus problemas e realizar suas tarefas do dia a dia, dentro de suas possibilidades.

- Área Meio Ambiente: foi a que obteve maior porcentagem na opção ponto forte $(74,3 \%)$, mostrando que a maioria procura estar em locais que lhes façam bem.

O que pode ser relatado com relação à aplicação do questionário de autoavaliação do funcionamento ocupacional (SAOF) é a dificuldade dos participantes em compreender algumas perguntas. De forma geral, houve entendimento da maioria dos participantes. Para alguns, porém, foi necessário que a pesquisadora explicasse e adaptasse algumas questões, como, por exemplo, na área 4, questão número 10, que pergunta se a pessoa está envolvida em seus papéis (seja de estudante, de trabalhador). Foi necessário explicar o que eram papéis e a presença de mais de uma variável no mesmo item, como, por exemplo, o item 21 (cuidar da higiene pessoal, cozinhar, lavar a roupa), o que fazia com que as pessoas tomassem esses exemplos como variáveis. Tal fato também foi relatado por Tedesco (2000).

Morais (2004) cita que seria mais fácil se as afirmativas fossem apresentadas como perguntas e as opções de respostas fossem substituídas por: bastante, mais ou menos e dificuldade. Relacionando esse comentário com o que foi aplicado nessa pesquisa, também seria considerável essa substituição, pois muitas vezes a pesquisadora precisou fazer essa troca para uma melhor compreensão.

Observa-se que em todas as áreas a alternativa mais escolhida foi "ponto forte" e na área 7 a definição de Meio Ambiente teve a média maior: 74,3\%. A menor média foi de $46,2 \%$ referente à área 5 , em se tratando de "ponto forte". A área com maior dificuldade foi a referente a valores, da área 2, com 20,5\%, e hábitos, da área 5, com 20\%. Nos estudos desenvolvidos por Tedesco (2000), também há 
semelhanças, pois uma das áreas com maior porcentagem de escore, necessidade de melhora, também foi a área 5 (hábitos).

Durante a entrevista, muitos queixaram-se da dificuldade de organizar o tempo (questão número 13) e ser flexível a respeito das mudanças ocorridas na rotina (número 15). Percebe-se que quase todo o desenvolvimento deste trabalho envolve esse fator: a mudança da rotina, horários o cotidiano da pessoa com IRC. Tal fato se confirma por esse questionário.

A dificuldade também apontada na área de valores permitia que essas pessoas entrassem em contato com questões mais subjetivas e com sua atual realidade, como ter objetivos para o futuro, fazer atividades que tenham significados, ou seja, pensar em quais objetivos poderiam ter e isto pode ser relacionado com as perdas que ocorrem com essas pessoas, pois, como cita Borges (2003), há perdas nas relações sociais, perdas financeiras, na capacidade física, nas atividades de lazer, podendo ocorrer remissões e exacerbações. Nesse caso, é necessário ajuda para que o paciente possa controlar a situação.

\subsection{A qualidade de vida}

De maneira resumida, as escalas apontaram para as diferenças não significativas na avaliação da qualidade de vida no domínio Psicológico. No domínio Fisico avaliaram ter melhor qualidade de vida os que não tem cônjuge, os que estão há menos de um ano em HD e os pacientes do sexo feminino (esta, aliás, é a única diferença observada entre os sexos). A instrução é importante para a qualidade de vida nos domínios Social, Meio Ambiente e Saúde em Geral. 
Os resultados obtidos apontaram para diferenças nas avaliações dos questionários, na qualidade de vida dessas pessoas principalmente em alguns aspectos como a escolaridade, tempo de HD, número de pessoas na residência e em relação ao sexo e situação marital.

Podemos discutir a qualidade de vida, em relação ao sexo, que o sexo feminino tem tendência a apresentar um escore maior $(62,9)$ e o masculino menor $(52,3)$, embora algumas pesquisas, como a de Martins e Cesarino (2005), mostrem que não houve diferenças estatisticamente significantes entre os sexos. Nesse estudo, parece que há diferença.

Em relação aos outros domínios (Psicológico, Relação Social e Meio Ambiente), o sexo feminino também apresenta tendência a maior média de escore, conforme mostra a Tabela 15.

Em relação à escolaridade, aos anos de estudo, as pessoas com maior escolaridade são as que apresentam tendência à média de escore maior, ou seja, uma melhor avaliação da qualidade de vida, pois, conforme relata Martins e Cesarino (2005), a escolaridade pode estar relacionada ao aspecto emocional e material como melhores condições de vida para o enfrentamento da doença. Quem tem maior escolaridade possui mais recursos intelectuais para uma melhor adaptação emocional diante das conseqüências da doença.

Em relação ao tempo de HD, o que se encontra na literatura, conforme relata Martins e Cesarino (2005), é que o componente físico está relacionado ao tempo de $H D$, pois quanto mais tempo a pessoa faz HD, mais comprometida fica a sua saúde física, e a pessoa aprende a enfrentar as dificuldades decorrentes do adoecimento.

Em seguida, para finalizar e confirmar os resultados acima, apresentam-se os resultados dos testes de comparação dos escores de qualidade de vida em relação 
aos quatro domínios quanto ao nível de significância. Os resultados mostraram que, em relação à situação marital, as pessoas sem cônjuge apresentam uma melhor qualidade de vida. Carreira e Marcom (2003) citam a situação financeira como um dos problemas a serem enfrentados, pois em muitas famílias onde há pessoas com IRC ocorre a diminuição da renda familiar. Como já citamos, há gastos com remédios e muitos chefes de família param de trabalhar. Portanto, conclui-se que as pessoas sem cônjuge e sem filhos podem não ter essa preocupação de um lar para sustentar, podendo obter uma melhor qualidade de vida. Tal fato pode também ser confirmado como no caso de residências com um menor número de pessoas, onde essas pessoas passam a usufruir de uma maior qualidade de vida, pelo mesmo motivo que relatamos.

Quanto ao tempo, as pessoas que fazem HD há menos de um ano apresentaram qualidade de vida maior que as que fazem há mais de um ano, ou seja, o resultado foi significativo, pois como já foi relatado nos estudos de Martins e Cesarino (2005), o domínio Físico de quem faz HD há mais de um ano torna-se prejudicado.

Em relação ao Psicológico, os resultados não foram significantes e, para finalizar, em relação ao domínio Meio Ambiente e social e aos resultados gerais os anos de instrução tiveram significância, pois as pessoas com mais anos de instrução apresentaram maior qualidade de vida. Como foi relatado no inicio da discussão, pode haver uma correlação entre os anos de estudo e os aspectos emocionais, sugerindo que as pessoas com maior escolaridade apresentam mais recursos para lidar com as conseqüências da IRC, desenvolvendo uma melhor qualidade de vida. 


\subsection{Considerações finais}

Dessa forma, constatou-se que os três instrumentos utilizados foram de fundamental importância e úteis para colher informações gerais sobre os IRCs, através dos questionários sócio-demográficos, assim como os específicos para qualidade de vida e funcionamento ocupacional. Através desses questionários, percebe-se que as informações apresentadas no inicio da pesquisa sobre as dificuldades enfrentadas como mudança no cotidiano, restrições alimentares, sessões de HD, realmente desestruturam o cotidiano e conseqüentemente a qualidade de vida dos IRCs, principalmente nos aspectos físicos, como o tempo de HD, escolaridade e situação marital.

O SAOF mostrou que áreas como valores e hábitos mostram que aspectos quanto à organização do tempo, à flexibilidade, quanto às mudanças da rotina, aos objetivos e às expectativas para o futuro, também foram os principais aspectos desestruturados quanto ao funcionamento ocupacional dessas pessoas.

Para Takatori (2001), ter projetos pessoais, sua colocação em prática e seu compartilhamento com outras pessoas compõem um dia-a-dia refletindo na história pessoal, necessário para a vida do sujeito.

A partir daí percebe-se que, mesmo diante das dificuldades, como ter um cotidiano alterado por horários de HD, restrições alimentares (em muitos casos a pessoa pára de trabalhar e de estudar), os IRCs podem sim, se necessário com ajuda de profissionais, desenvolver uma rotina de afazeres e construir projetos, fazer algo que tenha significado para si, ou seja, reconstruir seu cotidiano.

Considerando os recursos oferecidos e apresentados pela Terapia Ocupacional, e entendo esta como facilitadora para construção de idéias, em que a pessoa 
possa desenvolver novas potencialidades e habilidades ou algo que já existia e precisava apenas de um estímulo, de motivação, podemos sugeri-la como contribuição, sendo uma das alternativas para um melhor desempenho ocupacional e qualidade de vida para as pessoas com IRC. 
VI. REFERÊNCIAS BIBLIOGRÁFICAS 
ARREDONDO, A.; ICAZA, F.; RANGEL, R. Costos de Intervenciones para pacientes com Insuficiência Renal Crônica. Revista Saúde Pública, São Paulo, v.32, n.3, p.255-264,1998.

BENETTON, J.; FERRARI, S.; TEDESCO, S. Hábitos, cotidiano e Terapia Ocupacional. Revista do Centro de Estudos de Terapia Ocupacional CETO, São Paulo, ano 8, n.8, p.27-40, 2003.

BEZERRA, K.; PIANTINO, D; MORAIS, L. Relato de experiência: grupo de terapia ocupacional durante hemodiálise. Revista do Centro de Estudos de Terapia Ocupacional - CETO, São Paulo, ano 9, n.9, p.29-35, 2005.

BORGES, S.L.S. Dificuldades do adoecimento e do tratamento: sentidos produzidos com pessoas portadoras de Insuficiência Renal Crônica em um grupo de apoio. 2003. 130f. Dissertação (Mestrado em: Psicologia) - Faculdade de Filosofia, Ciências e Letras de Ribeirão Preto, Universidade de São Paulo, Ribeirão Preto, 2003.

CARREIRA L.; MARCON, S.S. Cotidiano e Trabalho: Concepções de indivíduos portadores de Insuficiência Renal Crônica e seus familiares. Revista Latino Americana de Enfermagem, Rio de Janeiro, v.11, n.6, p.823-831, 2003.

CUNHA, A.G. Dicionário Etimológico, Rio de Janeiro: Nova Fronteira, p.223,1982.

DRAIBE, S.A. Insuficiência Renal Crônica. In: Schor, N. Guia de Nefrologia. São Paulo: Manole, 2002.

FERRAZ, M.B. Qualidade de vida, conceito e um breve histórico. Revista Jovem Médico, São Paulo, v.4 , p.219-222, 1998.

FLECK, M.P.A. Versão em português dos instrumentos de avaliação de qualidade de vida (WHOQOL-100 e do WHOQOL- bref). Porto Alegre: UFRGS; 1998. Disponível em: <http//.www.ufrgs.br/psiq/whoqo14.html>. Acesso em: 25 de abril de 2005.

FLECK, M.P.A.; LOUZADA, S.; XAVIER, M.; CHACHAMOVICH, E.; VIEIRA, G.; SANTOS, L.; PINZON, V. Aplicação da versão em português do instrumento abreviado da avaliação da qualidade de vida "WHOQOL-bref". Revista Saúde Pública, São Paulo, v.34, n.2, p.178- 183, 2000.

HELLER, A. O cotidiano e a História, v.2. São Paulo: Paz e Terra, 2000. 
HOLLANDER, M.; WOLFE, D.A. Nonparametric statistical methods. (2 ${ }^{\underline{a}}$ ed.). New York: John Wiley \& Sons, 1999.

KIELHOFNER, G.; BARRETT, L. O modelo da ocupação humana. In: WILLARD; SPACKMAN. Terapia Ocupacional. Rio de Janeiro: Guanabara Koogan, 2002.

MARTINS, M.R.I.; CESARINO, C.B. Qualidade de vida de pessoas com doença renal crônica em tratamento hemodialítico. Revista Latino-Americana de Enfermagem, Ribeirão Preto, v.13, n.5, p.670-676, 2005.

MASTROPIETRO, A.P. Reconstrução do cotidiano de pacientes submetidos ao transplante de medula óssea: Readaptação funcional e reinserção ocupacional. 2003. 215f. Dissertação (Mestrado em: Psicologia) - Faculdade de Filosofia, Ciências e Letras de Ribeirão Preto, Universidade de São Paulo USP, Ribeirão Preto, 2003.

MEDEIROS, M.H. Terapia Ocupacional - Um enfoque epistemológico e social. São Paulo: Hucitec, 2003.

MEDRONHO, R.A.; CARVALHO, D.M.; BLOCH, K..; LUIZ, R.R.; WERNECK, G.L. Epidemiologia - São Paulo: Atheneu, 2002.

MINAYO, M.C.S.; HARTZ, Z.M.; BUSS, P.M. Qualidade de vida e saúde: um debate necessário. Ciência e Saúde Coletiva, Rio de Janeiro, v.5, n.1, p.7-18, 2000.

MINISTÉRIO DA SAÚDE. Doenças Renais Disponível em: <http://www.portalweb05saude.gov.br/portal/saúde>. Acessso em: 18 de outubro de 2002.

MORAIS, L.V. A vida cotidiana de mulheres com obesidade: a percepção da saúde e do funcionamento ocupacional. 2004. 129p. Dissertação (Mestrado em Saúde na Comunidade) - Faculdade de Medicina de Ribeirão Preto, Universidade de São Paulo, Ribeirão Preto, 2004.

NEISTADT; CREPEAU. Introdução a Terapia Ocupacional. In: WILLARD; SPACKMAN. Terapia Ocupacional. Rio de Janeiro: Guanabara Koogan, 2002.

NETTO, J.P.; CARVALHO, M.C. Cotidiano: Conhecimento e Crítica. $4^{\mathrm{a}}$ ed. São Paulo: Cortez, 1996.

OLIVEIRA, A.S. Crenças e afetos relacionados a algumas condições para qualidade de vida e insuficiência renal crônica (IRC): subsídios para uma abordagem psicossocial. 2000. 116p. Tese (Doutorado em Saúde Mental) Universidade Federal de São Carlos, Ribeirão Preto, 2000. 
PIERRATOS, A. Nocturnal home haemodialysis: na update on a 5- year experience. Nephrology Dialysis Transplantion, Canadá, v.14, n.12, 835-2840, 1999.

RUFFINO-NETO, A.R. Qualidade de vida: Compromisso Histórico da Epidemiologia. In: II Congresso Brasileiro de Epidemiologia, 1994, Belo Horizonte. Anais..., Belo Horizonte: Coopmece/ Abrasco,1994. p.12-18.

SESSO, R. Epidemiologia da Insuficiência Renal Crônica no Brasil. In: SCHOR, N. Guia de Nefrologia. São Paulo: Manole, 2002.

SOCIEDADE BRASILEIRA DE NEFROLOGIA (SBN) - Censo 2005, Centro de Diálise no Brasil. Disponível em: <http://www.sbn.org.br/censo>. Acesso em: 13 de março de 2006.

SOCIEDADE BRASILEIRA DE NEFROLOGIA (SBN), 2001. Disponível em: <http:www.sbn.org.br/publico/rim.htm>. Acesso em: 13 de janeiro de 2006.

TAKATORI, M. A Terapia Ocupacional no processo de reabilitação: Construção do cotidiano. O Mundo da Saúde, São Paulo, v.25, n.4, p.371-382, 2001.

TEDESCO, S.A. Estudo da validade e confiabilidade de um instrumento de Terapia Ocupacional: Auto-Avaliação do funcionamento Ocupacional (SAOF). 2000.133f. Dissertação (Mestrado em: Saúde Mental) - Escola Paulista de Medicina, Universidade Federal de São Paulo, São Paulo, 2000.

WEINER, P.; ZIDAN, F.; ZONDER, B. Hemodiálysis Treatment may Improve Inspiratory muscle strenght and endurance. J. Méd. Sci., v.33, p.134-38, 1997.

WIKIPÉDIA ENCICLOPÉDIA, 2006. Disponível em: <http://www.pt.wikipedia.org/ wiki/diálise_peritoneal>. Acesso em: 23 de julho de 2006. 


\section{ANEXOS}


ANEXO A: Parecer do Comitê de Ética

ANEXO B: Esclarecimento ao Sujeito da Pesquisa e Termo de Consentimento de Participação

ANEXO C: Questionário Sócio-Demográfico

ANEXO D: Auto avaliação do Funcionamento Ocupacional

ANEXO E: Versão em português do instrumento de avaliação de qualidade de vida (WHOQOL-bref) 


\section{(ANEXO A)}

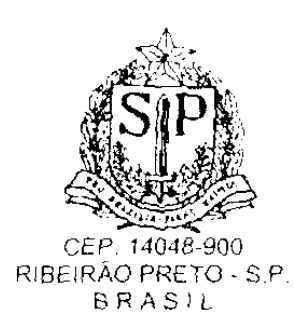

Orício $n^{\circ} 995 / 2005$

$\mathrm{CEP} / \mathrm{CDGC}$

Prezada Senhora:

\section{PARECER DO COMITÊ DE ÉTICA}

HOSPITAL DAS CLINIICAS DA FACULDADE DE MEDICINA DE RIBEIRÃO PRETO DA UNIVERSIDADE DE SÃO PAULO

CAMPUS UNIVERSITARIO - MONTE ALEGRE FONE: 602-1000- FAX (016i) 633-11.4.1

Ribeirão Preto, 14 de abril de 2005

O trabalho intitulado "O ESTUDO DO

COTIDIANO DE PESSOAS COM INSUFICIÊNCIA RENAL CRÔNICA (I.R.C.), EM HEMOdIÁlise NO SERVIÇO PÚBLICO DE SAÚdE", foi analisado pelo Comitè de Ética em Pesquisa, em sua 199" Reuniào Ordinária realizada em 11/04/2005, e enquadrado na categoria: APROVADO, bem como o Termo de Consentimento Livre e Esclarecido, de acordo com o Processo HCRP n ${ }^{\circ} 2108 / 2005$.

Aproveito a oportunidade para apresentar a

Vossa Scnhoria protestos de estima e consideraçăo.

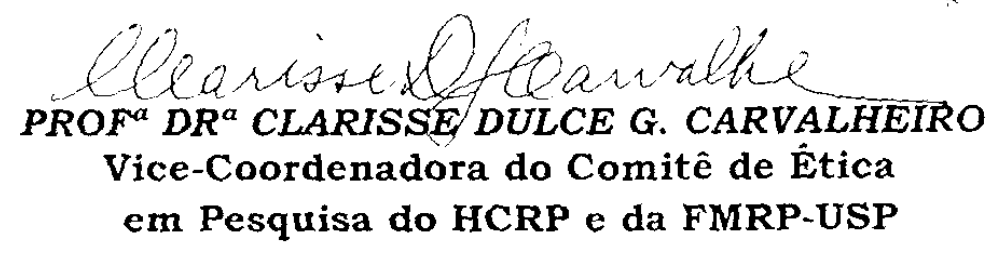

llustrissima Senhora

KARINA VIVIANI BEZERRA

PROF. DR. JAIR LICIO FERREIRA SANTOS (Orientador)

Depto. de Medicina Social

Pós-Graduacão em Ciencias Médicas

Em más 


\section{(ANEXO B)}

\section{ESCLARECIMENTO AO SUJEITO DA PESQUISA}

$O$ projeto de pesquisa " $O$ estudo do cotidiano de pessoas com insuficiência renal crônica (IRC.) em hemodiálise no serviço público de saúde" está sendo desenvolvido pela Terapeuta Ocupacional Karina Viviani Bezerra (crefito: 3/5754-TO), sob orientação do professor Jair Lício Ferreira Santos, docente do Departamento de Medicina Social da Faculdade de Medicina de Ribeirão Preto da Universidade de São Paulo.

Esta pesquisa constituirá na aplicação de três questionários aos pacientes em tratamento de hemodiálise, atendidos no $\mathrm{HC}$ da Faculdade de Medicina de Ribeirão Preto (HCFMRP) e no Serviço de Nefrologia de Ribeirão Preto (SENERP).

$O$ presente estudo traz como justificativa, as dificuldades enfrentadas pelas pessoas com insuficiência renal crônica (IRC), como restrição alimentar, desempenho social, como trabalho, estudo e lazer, ou seja, uma série de dificuldades quanto ao desempenho ocupacional.

A pesquisa tem como objetivo avaliar o cotidiano de pessoas com (IRC) em relação ao seu funcionamento ocupacional, em dois serviços públicos de saúde: UTR - Unidade de Hemodiálise e Transplante Renal do Hospital das Clinicas de Ribeirão Preto e no SENERP e avaliar a qualidade de vida dentro dos seguintes domínios: Físico, Psicológico, Social e Meio Ambiente.

Os participantes serão entrevistados no próprio local de atendimento durante a sessão de hemodiálise em horários previamente definidos. A entrevista durará em torno de 1 (uma) hora.

Um dos questionários aplicados consiste em perguntas envolvendo dados sócio-demográficos como: idade, tipo de união, renda familiar, procedência, entre outros. Há também mais dois questionários, aplicados também pela pesquisadora.

Os dois questionários envolvem questões em como a pessoa avalia sua qualidade de vida, sua rotina, hábitos, habilidades, valores pessoais, ou seja, tudo o que diz respeito ao seu dia a dia, ao seu modo de viver. A pesquisa não apresenta nenhum risco e desconforto aos participantes.

Dessa forma entende-se que a pesquisa tem o intuito de obter informações, em relação às dificuldades enfrentadas por essas pessoas, tendo como contribuição uma melhor assistência prestada a esta população.

Caso necessite de maiores informações, mesmo após a conclusão da sua participação, você poderá entrar em contato conosco, através do endereço abaixo.

Muito obrigada pela sua atenção.

Karina Viviani Bezerra.

Terapeuta Ocupacional
Prof. Dr. Jair Lício Ferreira Santos

Departamento de Medicina Social

Faculdade de Medicina de Rib. Preto Universidade de São Paulo 


\section{TERMO DE CONSENTIMENTO LIVRE}

Eu sido devidamente esclarecido sobre todas as condições que constam do documento "ESCLARECIMENTO AO SUJEITO DA PESQUISA", de que trata o projeto de pesquisa intitulado "O estudo do cotidiano de pessoas com insuficiência renal crônica (IRC.), em hemodiálise no serviço público de saúde". Que tem como pesquisadores responsáveis o prof. Dr. Jair Lício Ferreira Santos e a terapeuta ocupacional Karina Viviani Bezerra, especialmente no que diz respeito ao objetivo da pesquisa, aos procedimentos que serei submetido, aos riscos e aos benefícios, declaro que tenho pleno conhecimento dos direitos e das condições que me foram assegurados, a seguir relacionados:

1. Minha participação é voluntária e contribuirá para melhorar os serviços de saúde do município;

2. Não terei prejuízo ou punição por participar, ou deixar de participar deste estudo;

3. Terei a liberdade de não responder algumas questões se assim desejar, bem como terei a liberdade de desistir de minha participação no estudo, sem sofrer punição ou prejuízo por isso;

4. Minha participação na entrevista não me prejudicará na forma de atendimento médico que utilizo;

5. As informações que darei serão confidenciais e minha identidade jamais será conhecida ou divulgada para outras pessoas;

6. Todas as informações que fornecer serão anotadas em um formulário mantendo o meu anonimato, e que posteriormente serão codificadas e analisadas de uma forma coletiva, agrupando todos os participantes;

7. A garantia de receber a resposta a qualquer pergunta ou esclarecimento de qualquer dúvida a respeito dos procedimentos, riscos, benefícios e de outras situações relacionadas com a pesquisa e o tratamento a que serei submetido;

8. O compromisso de que serei devidamente acompanhado e assistido durante todo o período de minha participação no projeto.

Declaro, ainda que concordo inteiramente com as condições que me foram apresentadas e que, livremente, manifesto a minha vontade em participar do referido projeto.

Ribeirão Preto, de de 2005 


\section{(ANEXO C)}

\section{QUESTIONÁRIO SÓCIO-DEMOGRÁFICO}

1. Idade : anos

2. Sexo:( ) M ( ) F

3. Tipo de união: ( ) Solteiro ( ) Vivendo consensualmente ( ) Casado ( ) Separado ( ) Viúvo

4. Cidade em que reside :

5. Número de pessoas que moram na casa :

6. Escolaridade $: n^{\circ}$ de anos que estudou

7. Ocupação antes da hemodiálise :

8. Ocupação atual :

9. Desempenha alguma atividade ? Qual ?

10. Renda individual $(R \$)$ :
( ) até 300,00
( ) 300,00 a 450,00
( ) 450,00 a 600,00
( ) 600,00 a 750,00
( ) 750,00 a 900,00
( ) 900,00 a 1050,00
( ) Acima de 1050,00
( ) Não se aplica

11. Renda familiar $(R \$)$ :
( ) até 300,00
( ) 300,00 a 450,00
( ) 450,00 a 600,00
( ) 600,00 a 750,00
( ) 750,00 a 900,00
( ) 900,00 a 1050,00
( ) Acima de 1050,00
( ) Não se aplica

12. Há quanto tempo está em hemodiálise?

13. Conta com pessoas que o auxiliam no cotidiano e / ou tratamento? Quem?

14. Qual meio de transporte utilizado para ir até o local da hemodiálise ?

15. Apresenta algum outro problema de saúde? Qual ? 
(ANEXO D)

AUTO- AVALIAÇÃO DO FUNCIONAMENTO OCUPACIONAL

SAOF

Prontuário $\mathrm{N}^{\circ}$. :

Nome :

Data :

1

Local da entrevista : 


\section{AUTO-AVALIAÇÃO DO FUNCIONAMENTO OCUPACIONAL}

O OBJETIVO DESTA AVALIAÇÃO É:

*Identificar os PONTOS FORTES no seu funcionamento diário;

(áreas em que você tem desempenho muito bom)

* Identificar ÀREAS ADEQUADAS DE FUNCIONAMENTO;

(áreas em que você tem um desempenho bom)

*Identificar ÀREAS PROBLEMÁTICAS no seu funcionamento diário;

(áreas em que você apresenta dificuldade)

INSTRUÇÕES

Nesta avaliação pede-se para você pensar sobre 7 categorias de Funcionamento. Siga os seguintes passos para cada uma dessas categorias:

1. Leia a definição de categoria de funcionamento ocupacional .

2. Considere a lista de áreas de Funcionamento ocupacional que se relacionam com a definição.

3. Ao lado de cada afirmação, assinale apenas um espaço indicando se esta área é:

* SEU PONTO FORTE

* ÁREA ADEQUADA DE FUNCIONAMENTO

*ÁREA QUE NECESSITA SER MELHORADA 


\section{AUTO- AVALIAÇÃO DO FUNCIONAMENTO OCUPACIONAL}

\section{Definição de Causalidade Pessoal}

Essa área de funcionamento refere-se à forma como você vê a si mesmo e as suas experiências de falhar ou ter sucesso em suas ações. Esta área também inclui a sua opinião sobre sua capacidade de auto-controle, inclusive como você lida com acontecimentos frustrantes e como você toma suas decisões.

\section{Definição de Valores}

Esta área é definida pelas atividades que são importantes para você e os padrões e os objetivos que você estabelece para si próprio.

\section{Definição de seus Interesses}

Esta área está relacionada às atividades que você gosta.

\section{Definição de Papéis}

Esta área abrange os vários papéis que você desempenha em sua vida, tais como ser estudante ou trabalhador. Também inclui o conhecimento e o desempenho de comportamentos e habilidades necessárias a cada atuação. Os papéis podem funcionar de maneira a tornar a vida mais agradável ou a desencadear problemas e estresse.

\section{Definição dos Hábitos}

Esta área refere-se aos atos rotineiros, tais como cuidar da higiene pessoal, 
estudar ou cumprir seus horários. Os hábitos ajudam você a se organizar e executar as tarefas do cotidiano. Os hábitos também auxiliam o funcionamento dos seus papéis. Por exemplo, bons hábitos de estudo ajudam o desempenho do papel de estudante. Essa área também envolve sua capacidade para ser flexível quando as coisas não acontecem conforme o planejado.

\section{Definições das Habilidades}

Estas são suas habilidades físicas e mentais que ajudam você a se expressar, a estabelecer contatos sociais e a agir.

\section{Definição do Meio Ambiente}

Esta área refere-se à variedade de locais onde passa o se tempo. Esses locais podem incluir pessoas (por ex., familiares, amigos), objetos (por ex., móveis como: sofá, mesa), recursos da comunidade (por ex., igreja, clube). Os locais podem tanto ajudar como atrapalhar a sua capacidade de desenvolvimento e funcionamento. 


\section{AUTO- AVALIAÇÃO DO FUNCIONAMENTO OCUPACIONAL}

Folha de Resposta - Versão completa

I-A. Definição de Causalidade Pessoal: Esta área refere-se à forma como você vê a si mesmo e as suas expectativas de falhar ou ter sucesso em suas ações. Esta área também inclui a sua opinião sobre sua capacidade de auto-controle, inclusive como você lida com acontecimentos frustrantes e como você toma suas decisões.

\section{I-B. Avalie o seu funcionamento:}

\begin{tabular}{|l|l|l|l|}
\hline \multicolumn{1}{|c|}{$\begin{array}{c}\text { ÁREA DE FUNÇÃO } \\
\text { OUPACIONAL }\end{array}$} & $\begin{array}{c}\text { PONTO } \\
\text { FORTE }\end{array}$ & ADEQUADA & $\begin{array}{c}\text { NECESSIDADE } \\
\text { DE MELHORA }\end{array}$ \\
\hline 1. Causalidade Pessoal & & \\
1. Conhecer minhas habilidades & & & \\
\hline $\begin{array}{l}\text { 2. Esperar sucesso dos meus } \\
\text { esforços ao invés do fracasso }\end{array}$ & & & \\
\hline $\begin{array}{l}\text { 3. Acreditar que eu posso realizar } \\
\text { coisas no trabalho, na escola, em } \\
\text { casa ou em momento de lazer. }\end{array}$ & & & \\
\hline
\end{tabular}


II-A. Definicãa de Valores: Esta área é definida pelas atividades que são importantes para você e os padrões e os objetivos que você estabelece para si próprio.

II-B. Avalie o seu funcionamento

\begin{tabular}{|c|c|c|c|}
\hline $\begin{array}{c}\text { ÁREA DE FUNÇÃO } \\
\text { OCUPACIONAL }\end{array}$ & $\begin{array}{l}\text { PONTO } \\
\text { FORTE }\end{array}$ & ADEQUADA & $\begin{array}{l}\text { NECESSIDADE } \\
\text { DE MELHORA }\end{array}$ \\
\hline II. Valores & & & \\
\hline $\begin{array}{l}\text { 4. Fazer atividades que } \\
\text { tenham significado para } \\
\text { mim }\end{array}$ & & & \\
\hline $\begin{array}{l}\text { 5. Ter objetivos para o } \\
\text { futuro }\end{array}$ & & & \\
\hline $\begin{array}{l}\text { 6. Ter expectativas realistas } \\
\text { a meu respeito. }\end{array}$ & & & \\
\hline
\end{tabular}


III.A. Definição de Interesses: Esta área está relacionada as atividades que você gosta.

III-B. Avalie seu funcionamento

\begin{tabular}{|l|l|l|l|}
\hline $\begin{array}{c}\text { ȦREA DE FUNÇÃO } \\
\text { OCUPACIONAL }\end{array}$ & $\begin{array}{c}\text { PONTO } \\
\text { FORTE }\end{array}$ & ADEQUADA & $\begin{array}{c}\text { NECESSIDADE } \\
\text { DE MELHORA }\end{array}$ \\
\hline $\begin{array}{l}\text { III. Interesses } \\
\text { 7. Identificar meus } \\
\text { interesses. }\end{array}$ & & & \\
\hline $\begin{array}{l}\text { 8. Ter interesses variados. } \\
\text { 9. Participar de meus } \\
\text { interesses. }\end{array}$ & & & \\
\hline
\end{tabular}


IV-A. Definição de Papéis: Esta área abrange os vários papéis que você desempenha em sua vida, tais como ser estudante ou trabalhador. Também inclui o conhecimento e o desempenho de comportamentos e habilidades necessários a cada atuação. Os papéis podem funcionar de maneira a tornar a vida agradável ou a desencadear problemas estresse.

IV-B. Avalie o seu funcionamento

\begin{tabular}{|l|l|l|l|}
\hline ÀREA DE FUNÇÃO OCUPACIONAL & $\begin{array}{c}\text { PONTO } \\
\text { FORTE }\end{array}$ & ADEQUADA & $\begin{array}{c}\text { NECESSIDADE } \\
\text { DE MELHORA }\end{array}$ \\
\hline IV. Papéis & & & \\
$\begin{array}{l}\text { 10. Estar envolvido em papéis. } \\
\text { (ex., de estudante, de trabalhador, de } \\
\text { amigo, de familiar, de alguém que } \\
\text { sustenta o lar). }\end{array}$ & & \\
\hline $\begin{array}{l}\text { 11.Conhecer e atingir as expectativas } \\
\text { de meus papéis }\end{array}$ & & & \\
\hline $\begin{array}{l}\text { 12.Ter um equilíbrio saudável dos } \\
\text { papéis na minha vida. }\end{array}$ & & & \\
\end{tabular}


V-A. Definição de hábitos: Esta área refere-se aos atos rotineiros, tais como cuidar de higiene pessoal, estudar ou cumprir seus horários. Os hábitos ajudam você a se organizar executar as tarefas do cotidiano. Os hábitos também auxiliam o funcionamento dos papéis. Por exemplo: bons hábitos de estudo ajudam o desempenho do papel de estudante. Esta área também envolve sua capacidade para ser flexível quando as coisas não acontecem conforme o planejado.

\section{V-B. Avalie seu funcionamento}

\begin{tabular}{|l|l|l|l|}
\hline ÀREA DE FUNÇÃO OCUPACIONAL & $\begin{array}{l}\text { PONTO } \\
\text { FORTE }\end{array}$ & ADEQUADA & $\begin{array}{c}\text { NECESSIDADE } \\
\text { DE MELHORA }\end{array}$ \\
\hline$\underline{\text { V. Hábitos }}$ & & & \\
13. Organizar meu tempo & & \\
\hline $\begin{array}{l}\text { 14. Ter hábitos que ajudem no } \\
\text { sucesso dos meus papéis. }\end{array}$ & & & \\
\hline $\begin{array}{l}\text { 15. Ser flexível a respeito das } \\
\text { mudanças na minha rotina. }\end{array}$ & & & \\
\hline
\end{tabular}


VI-A. Definicão de Habilidades: Estas são suas habilidades físicas e mentais que ajudam a se expressar, a estabelecer contato social e a agir.

VI- B. Avalie seu funcionamento

\begin{tabular}{|l|l|l|l|}
\hline ÀREA DE FUNÇÃO OCUPACIONAL & $\begin{array}{l}\text { PONTO } \\
\text { FORTE }\end{array}$ & ADEQUADA & $\begin{array}{c}\text { NECESSIDADE } \\
\text { DE MELHORA }\end{array}$ \\
\hline VI. Habilidades & & & \\
\hline 16. Expressar-me para os outros. & & & \\
\hline $\begin{array}{l}\text { 17. Socializar-me com outra pessoa } \\
\text { ou em grupo. }\end{array}$ & & & \\
\hline $\begin{array}{l}\text { 18. Planejar antes de agir. } \\
\text { 19. Concentrar-me e completar meu } \\
\text { trabalho. }\end{array}$ & & & \\
\hline $\begin{array}{l}\text { 20. Identificar problemas, as suas } \\
\text { soluções e agir. }\end{array}$ & & & \\
\hline $\begin{array}{l}\text { 21. Desempenhar tarefas cotidianas } \\
\text { (por ex., cuidar da minha higiene } \\
\text { pessoal, cozinhar, lavar roupa, } \\
\text { organizar gastos de dinheiro). }\end{array}$ & & & \\
\hline $\begin{array}{l}\text { 22. Ser fisicamente capaz de fazer o } \\
\text { que precisar ser feito. }\end{array}$ & & & \\
\hline
\end{tabular}


VII-A. Definicão do Meio Ambiente: Esta área refere-se à variedade de locais onde você passa seu tempo. Esses locais podem incluir pessoas (por ex. familiares, amigos), objetos (por ex.: móveis como: sofá, mesa) e recursos da comunidade (por ex.: igreja, clube). Os locais podem tanto ajudar como atrapalhar a sua capacidade de desenvolvimento.

VII-B. Avalie seu funcionamento

\begin{tabular}{|l|l|l|l|}
\hline ÀREA DE FUNÇÃO OCUPACIONAL & $\begin{array}{l}\text { PONTO } \\
\text { FORTE }\end{array}$ & ADEQUADA & $\begin{array}{c}\text { NECESSIDADE } \\
\text { DE MELHORA }\end{array}$ \\
\hline VIl. Meio ambiente & & & \\
\hline 23. Estar em ambientes favoráveis. & & & \\
& & & \\
\hline
\end{tabular}




\title{
(ANEXO E)
}

\section{Instrumento de medida Genérico para Avaliação da Qualidade de Vida: "Word Organization Quality of Life" WHOQOL- bref.}

\author{
Instruções
}

Este questionário é sobre como você se sente a respeito de sua qualidade de vida, saúde e outras áreas de sua vida. Por favor responda a todas as questões. Se você não tem certeza sobre que resposta dar em uma questão, por favor, escolha entre as alternativas a que lhe parece mais apropriada. Esta, muitas vezes, poderá ser sua primeira escolha.

Por favor, tenha em mente seus valores, aspirações, prazeres e preocupações. Nós estamos perguntando o que você acha de sua vida, tomando como referência as duas últimas semanas. Por exemplo, pensando nas últimas duas semanas, uma questão poderia ser:

\begin{tabular}{|c|c|c|c|c|c|}
\hline & nada & Muito pouco & médio & muito & completamente \\
\hline $\begin{array}{c}\text { Você recebe dos outros o } \\
\text { apoio de que necessita? }\end{array}$ & 1 & 2 & 3 & 4 & 5 \\
\hline
\end{tabular}

Você deve circular o número que melhor corresponde ao quanto você recebe dos outros o apoio de que necessita nestas últimas duas semanas.

Portanto, você deve circular o número 4 se você recebeu "muito" apoio como abaixo.

\begin{tabular}{|c|c|c|c|c|c|}
\hline & nada & Muito pouco & médio & muito & completamente \\
\hline $\begin{array}{c}\text { Você recebe dos outros o } \\
\text { apoio de que necessita? }\end{array}$ & 1 & 2 & 3 & 4 & 5 \\
\hline
\end{tabular}

Você deve circular o número 1 se você não recebeu "nada" de apoio.

Por favor, leia cada questão, veja o que você acha e circule no número e lhe parece a melhor resposta.

\begin{tabular}{|l|l|c|c|c|c|c|}
\hline & Muito ruim & Ruim & $\begin{array}{c}\text { Nem ruim } \\
\text { nem boa }\end{array}$ & Boa & Muito boa \\
\hline 1 & $\begin{array}{l}\text { Como você avaliaria sua } \\
\text { qualidade de vida? }\end{array}$ & 1 & 2 & 3 & 4 & 5 \\
\hline
\end{tabular}

\begin{tabular}{|l|l|c|c|c|c|c|}
\hline & & $\begin{array}{c}\text { Muito } \\
\text { insatisfeito }\end{array}$ & Insatisfeito & $\begin{array}{c}\text { Nem satisfeito } \\
\text { nem insatisfeito }\end{array}$ & Satisfeito & $\begin{array}{c}\text { Muito } \\
\text { satisfeito }\end{array}$ \\
\hline 2 & $\begin{array}{l}\text { Quão satisfeito(a) você } \\
\text { está com a sua saúde? }\end{array}$ & 1 & 2 & 3 & 4 & 5 \\
\hline
\end{tabular}

As questões seguintes são sobre o quanto você tem sentido algumas coisas nas últimas duas semanas.

\begin{tabular}{|c|c|c|c|c|c|c|}
\hline & & Nada & $\begin{array}{l}\text { Muito } \\
\text { pouco }\end{array}$ & $\begin{array}{l}\text { Mais ou } \\
\text { menos }\end{array}$ & Bastante & Extremamente \\
\hline 3 & $\begin{array}{l}\text { Em que medida você acha que } \\
\text { sua dor (física) impede você de } \\
\text { fazer o que você precisa? }\end{array}$ & 1 & 2 & 3 & 4 & 5 \\
\hline 4 & $\begin{array}{l}\text { O quanto você precisa de algum } \\
\text { tratamento médico para levar sua } \\
\text { vida diária? }\end{array}$ & 1 & 2 & 3 & 4 & 5 \\
\hline 5 & O quanto você aproveita a vida? & 1 & 2 & 3 & 4 & 5 \\
\hline 6 & $\begin{array}{c}\text { Em que medida você acha que a } \\
\text { sua vida tem sentido? }\end{array}$ & 1 & 2 & 3 & 4 & 5 \\
\hline
\end{tabular}




\begin{tabular}{|c|c|c|c|c|c|c|}
\hline & Nada & $\begin{array}{c}\text { Muito } \\
\text { pouco }\end{array}$ & Mais ou & Bastante & Extremamente \\
\hline 7 & $\begin{array}{c}\text { O quanto você consegue se } \\
\text { concentrar? }\end{array}$ & 1 & 2 & 3 & 4 & 5 \\
\hline 8 & $\begin{array}{c}\text { Quão seguro(a) você se sente em } \\
\text { sua vida diária? }\end{array}$ & 1 & 2 & 3 & 4 & 5 \\
\hline 9 & $\begin{array}{l}\text { Quão saudável é o seu ambiente } \\
\text { físico (clima, barulho, poluição, } \\
\text { atrativos)? }\end{array}$ & 1 & 2 & 3 & 4 & 5 \\
\hline
\end{tabular}

As questões seguintes perguntam sobre quão completamente você tem sentido ou é capaz de fazer certas coisas nestas últimas duas semanas.

\begin{tabular}{|c|c|c|c|c|c|c|}
\hline & & Nada & $\begin{array}{c}\text { Muito } \\
\text { pouco }\end{array}$ & Médio & Muito & Completamente \\
\hline 10 & $\begin{array}{c}\text { Você tem energia suficiente } \\
\text { para seu dia-a- dia? }\end{array}$ & 1 & 2 & 3 & 4 & 5 \\
\hline 11 & $\begin{array}{c}\text { Você é capaz de aceitar sua } \\
\text { aparência física? }\end{array}$ & 1 & 2 & 3 & 4 & 5 \\
\hline 12 & $\begin{array}{c}\text { Você tem dinheiro suficiente } \\
\text { para satisfazer suas } \\
\text { necessidades? }\end{array}$ & 1 & 2 & 3 & 4 & 5 \\
\hline 13 & $\begin{array}{c}\text { Quão disponíveis para você } \\
\text { estão as informações que } \\
\text { precisa no seu dia-a-dia? }\end{array}$ & 1 & 2 & 3 & 4 & 5 \\
\hline $\begin{array}{c}\text { Em que medida você tem } \\
\text { oportunidades de atividade de } \\
\text { lazer? }\end{array}$ & 1 & 2 & 3 & 4 & 5 \\
\hline
\end{tabular}

As questões seguintes perguntam sobre quão bem ou satisfeito você se sentiu a respeito de vários aspectos de sua vida nas últimas duas semanas.

\begin{tabular}{|l|c|c|c|c|c|c|}
\hline & & $\begin{array}{c}\text { Muito } \\
\text { ruim }\end{array}$ & Ruim & $\begin{array}{c}\text { Nem ruim } \\
\text { Nem bom }\end{array}$ & Bom & Muito bom \\
\hline 15 & $\begin{array}{c}\text { Quão bem você é capaz de se } \\
\text { locomover? }\end{array}$ & 1 & 2 & 3 & 4 & 5 \\
\hline
\end{tabular}




\begin{tabular}{|c|c|c|c|c|c|c|}
\hline & & $\begin{array}{l}\text { Muito } \\
\text { insatisfeito }\end{array}$ & Insatisfeito & $\begin{array}{l}\text { Nem satisfeito } \\
\text { nem insatisfeito }\end{array}$ & Satisfeito & Muito satisfeito \\
\hline 16 & $\begin{array}{c}\text { Quão satisfeito(a) você está } \\
\text { com o seu sono? }\end{array}$ & 1 & 2 & 3 & 4 & 5 \\
\hline 17 & $\begin{array}{l}\text { Quão satisfeito(a) você está } \\
\text { com sua capacidade de } \\
\text { desempenhar as atividades do } \\
\text { seu dia-a-dia? }\end{array}$ & 1 & 2 & 3 & 4 & 5 \\
\hline 18 & $\begin{array}{c}\text { Quão satisfeito(a) você está } \\
\text { com sua capacidade para o } \\
\text { trabalho? }\end{array}$ & 1 & 2 & 3 & 4 & 5 \\
\hline 19 & $\begin{array}{c}\text { Quão satisfeito(a) você está } \\
\text { consigo mesmo? }\end{array}$ & 1 & 2 & 3 & 4 & 5 \\
\hline 20 & $\begin{array}{c}\text { Quão satisfeito(a) você está } \\
\text { com suas relações pessoais } \\
\text { (amigos, parentes, } \\
\text { conhecidos, colegas)? }\end{array}$ & 1 & 2 & 3 & 4 & 5 \\
\hline 21 & $\begin{array}{c}\text { Quão satisfeito(a) você está } \\
\text { com sua vida sexual? }\end{array}$ & 1 & 2 & 3 & 4 & 5 \\
\hline 22 & $\begin{array}{l}\text { Quão satisfeito(a) você está } \\
\text { com } \\
\text { o apoio que você recebe de } \\
\text { seus amigos? }\end{array}$ & 1 & 2 & 3 & 4 & 5 \\
\hline 23 & $\begin{array}{l}\text { Quão satisfeito(a) você está } \\
\text { com } \\
\text { as condições do local onde } \\
\text { mora? }\end{array}$ & 1 & 2 & 3 & 4 & 5 \\
\hline 24 & $\begin{array}{l}\text { Quão satisfeito(a) você está } \\
\text { com o } \\
\text { seu acesso aos serviços de } \\
\text { saúde? }\end{array}$ & 1 & 2 & 3 & 4 & 5 \\
\hline 25 & $\begin{array}{l}\text { Quão satisfeito(a) você está } \\
\text { com } \\
\text { o seu meio de transporte? }\end{array}$ & 1 & 2 & 3 & 4 & 5 \\
\hline
\end{tabular}

As questões seguintes referem-se a com que freqüência você sentiu ou experimentou certas coisas nas últimas duas semanas.

\begin{tabular}{|c|c|c|c|c|c|c|}
\hline & nunca & $\begin{array}{c}\text { Algumas } \\
\text { vezes }\end{array}$ & freqüentemente & $\begin{array}{c}\text { muito } \\
\text { freqüente } \\
\text { mente }\end{array}$ & sempre \\
\hline 26 & $\begin{array}{c}\text { Com que freqüência você tem } \\
\text { sentimentos negativos tais } \\
\text { como mau humor, desespero, } \\
\text { ansiedade, depressão? }\end{array}$ & 1 & 2 & 3 & 4 & 5 \\
\hline
\end{tabular}

Alguém the ajudou a preencher este questionário?

Quanto tempo você levou para preencher este questionário?

\section{Você tem algum comentário sobre o questionário?}

\section{OBRIGADA PELA SUA COLABORAÇÃO}




\section{EDITAC}

Editoração de Trabalhos Acadêmicos

(16) 3941.3802 | 9118.1914

Editac2006@yahoo.com.br

Impressão, encadernação, revisão, tradução, diagramação, desenhos, tabelas, adequação a normas, digitação e suporte integral ao pesquisador. 